\title{
Whole Root Transcriptomic Analysis Suggests a Role for Auxin Pathways in Resistance to Ralstonia solanacearum in Tomato
}

\author{
Elizabeth French, Bong-Suk Kim, Katherine Rivera-Zuluaga, and Anjali S. Iyer-Pascuzzi ${ }^{+}$ \\ Purdue University, Department of Botany and Plant Pathology, 915 W. State Street, West Lafayette, IN 47907, U.S.A.
}

Accepted 15 November 2017.

\begin{abstract}
The soilborne pathogen Ralstonia solanacearum is the causal agent of bacterial wilt and causes significant crop loss in the Solanaceae family. The pathogen first infects roots, which are a critical source of resistance in tomato (Solanum lycopersicum L.). Roots of both resistant and susceptible plants are colonized by the pathogen, yet rootstocks can provide significant levels of resistance. Currently, mechanisms of this 'root-mediated resistance' remain largely unknown. To identify the molecular basis of this resistance, we analyzed the genome-wide transcriptional response of roots of resistant 'Hawaii 7996' and susceptible 'West Virginia 700' (WV) tomatoes at multiple timepoints after inoculation with $R$. solanacearum. We found that defense pathways in roots of the resistant Hawaii 7996 are activated earlier and more strongly than roots of susceptible WV. Further, auxin signaling and transport pathways are suppressed in roots of the resistant variety. Functional analysis of an auxin transport mutant in tomato revealed a role for auxin pathways in bacterial wilt. Together, our results suggest that roots mediate resistance to $\boldsymbol{R}$. solanacearum through genome-wide transcriptomic changes that result in strong activation of defense genes and alteration of auxin pathways.
\end{abstract}

The soilborne betaproteobacterium Ralstonia solanacearum is the causal agent of bacterial wilt and has been ranked as one of the top ten most destructive plant bacterial pathogens of all time (Mansfield et al. 2012). The pathogen infects over 200 plant species in 50 families but is particularly devastating to members of the Solanaceae family (Hayward 1991; Huet 2014). $R$. solanacearum is a vascular pathogen that first colonizes the root surface and subsequently enters the root of both resistant and susceptible plants through small natural wounds or root tips

Elizabeth French and Bong-Suk Kim contributed equally to this work.

The RNA-seq data in this study has been submitted to the Short Read Archive (SRA) at the National Center for Biotechnology Information under project number SRP078159.

${ }^{\dagger}$ Corresponding author: Anjali S. Iyer-Pascuzzi; E-mail: asi2@purdue.edu

Funding: This work was funded by a grant from the Foundation for Food and Agriculture Research, start-up funds from Purdue University, Hatch funds, and a National Science Foundation Graduate Research Fellowship DGE-1333468.

*The $\boldsymbol{e}$-Xtra logo stands for "electronic extra" and indicates that three supplementary figures and six supplementary tables are published online.

(c) 2018 The American Phytopathological Society
(Genin 2010). The bacterium secretes cell wall-degrading enzymes and eventually spreads into the vascular system, in which it moves to the shoot via the flow of xylem fluid (Genin 2010; Genin and Denny 2012). As bacteria multiply, they secrete exopolysaccharide (Genin 2010; Genin and Denny 2012), which likely leads to physical xylem blockage and aboveground wilting. Resistant plants are able to delay colonization of the root vasculature (Caldwell et al. 2017), but the molecular responses involved in this delay are not clear. Here, we use RNA-seq and mutant analysis to understand responses to $R$. solanacearum in roots of resistant and susceptible tomato genotypes.

In tomato, resistance to $R$. solanacearum is quantitative (Carmeille et al. 2006; Danesh et al. 1994; Kim et al. 2016; Thoquet et al. 1996a and b; Wang et al. 2000, 2013), but no quantitative trait loci (QTL) for resistance have been cloned. Microarray analysis of genes differentially expressed in tomato stems $24 \mathrm{~h}$ after infection showed that $R$. solanacearum activates defense, hormone, and lignin pathways in resistant tomato stems (Ishihara et al. 2012). Surprisingly, no differentially expressed genes (DEGs) (fold change $>2$ ) were identified in susceptible stems after infection (Ishihara et al. 2012).

Despite the prevalence of soilborne pathogens and root diseases, most work in plant-pathogen interactions has focused on the aboveground portion of the plant. This is likely due to the hidden nature of roots and the visible aboveground disease phenotypes that often result from root infection. However, recent reports indicate that roots also have a robust immune system that functions to protect the plant from soilborne pathogens. For example, Arabidopsis roots can recognize microbe-associated molecular patterns (MAMPs) from pathogenic bacteria (Millet et al. 2010). In addition, roots infected with nematodes, which colonize root cortex tissue, can activate both MAMP-triggered immunity (Teixeira et al. 2016) and effector-triggered immunity (Goverse and Smant 2014; Mitchum et al. 2013). Tomato roots also appear to mount a defense response to $R$. solanacearum, because resistant rootstocks grafted to susceptible scions result in scions that are resistant to $R$. solanacearum and do not wilt (McAvoy et al. 2012; Rivard et al. 2012).

One approach to uncover the mechanisms of resistance in tomato roots to $R$. solanacearum is the analysis of whole-genome transcriptional responses. In resistant and susceptible accessions of a wild potato species, Solanum commersonii, transcriptome analysis 3 to 4 days after inoculation with $R$. solanacearum identified 221 genes in the resistant accession and 644 genes in the susceptible one that respond to infection (Zuluaga et al. 2015). In both accessions, genes that function in development were primarily downregulated, while those in the Gene Ontology (GO) category 'biotic stress' were mainly upregulated after infection (Zuluaga et al. 2015). In contrast, in a timecourse of peanut root 
infection, the expression patterns of many defense genes, including leucine-rich repeat (LRR) kinases and resistance $(R)$ genes, were downregulated in both resistant and susceptible peanut genotypes (Chen et al. 2014). Carbohydrate metabolism was repressed after infection in roots of both resistant and susceptible peanut roots but was more strongly inhibited in resistant roots (Chen et al. 2014). This suggests that the mechanisms of root-mediated resistance may differ among plant species.

The plant hormone auxin can have both positive and negative effects on plant defense (Fu and Wang 2011; Kazan and Manners 2009; Ludwig-Müller 2015). Plant resistance to some necrotrophic pathogens requires auxin signaling (Llorente et al. 2008; Qi et al. 2012; Tiryaki and Staswick 2002), but multiple reports have revealed a relationship between plant susceptibility to biotrophic pathogens and increased auxin accumulation or signaling (Chen et al. 2007; Ding et al. 2008; Fu and Wang 2011; O'Donnell et al. 2003; Navarro et al. 2006). Many phytopathogens produce auxin (Ludwig-Müller 2015; Spaepen et al. 2007), and this probably includes $R$. solanacearum (Valls et al. 2006). Exogenous treatment with auxin or auxin analogs increases disease symptoms caused by Pseudomonas syringae in Arabidopsis (Chen et al. 2007; Navarro et al. 2006) and increases rice susceptibility to Xanthomonas oryzae pv. oryzae (Ding et al. 2008), X. oryzae pv. oryzicola, and Magnaporthe grisea (Fu and Wang 2011). In Arabidopsis, overexpression of the AvrRpt2 type III effector from Pseudomonas syringae changes auxin-related developmental phenotypes (Chen et al. 2007) through the ability of AvrRpt 2 to promote degradation of an AUXIN/INDOLE-3-ACETIC-ACID (AUX/IAA) transcription factor, AXR2/IAA7, which represses auxin responses (Cui et al. 2013).

Suppression of auxin signaling may be particularly important in plant defense against vascular wilt pathogens. Several Arabidopsis auxin signaling and transport mutants are resistant to the soilborne vascular wilt pathogen Fusarium oxysporum (Kidd et al. 2011), and the walls are thin (watl) mutant of Arabidopsis is resistant to multiple vascular wilt pathogens, including $R$. solanacearum (Denance et al. 2012). The watl mutant has decreased levels of auxin in roots (Denance et al. 2012) and the base of stems (Ranocha et al. 2010), and the gene was recently shown to encode a vacuolar auxin transporter (Ranocha et al. 2013). WAT1 is expressed in the root pericycle and lateral root primordium (Denance et al. 2012), suggesting that auxin homeostasis within these tissues is particularly important for bacterial wilt resistance.

In this study, we aimed to identify the transcriptional response of resistant and susceptible tomato roots to $R$. solanacearum infection at $24 \mathrm{~h}$ and $48 \mathrm{~h}$ postinoculation (hpi). We identified the responsive genes in resistant and susceptible accessions independently and compared the responses. We show that resistant tomato roots activate defense pathways and terpene biosynthesis genes and suppress auxin signaling and transport pathways in response to $R$. solanacearum. In contrast, susceptible tomato roots activate defense response marker genes later and at a lower fold change, and genes required for root growth are suppressed by $48 \mathrm{hpi}$. Consistent with our finding that auxin pathways are suppressed in resistant roots, we show that a tomato auxin transport mutant in a susceptible wildtype background is resistant to $R$. solanacearum. Our data suggest that tomato roots mediate resistance to $R$. solanacearum, in part, through the suppression of auxin pathways.

\section{RESULTS}

Roots of resistant and susceptible tomato plants have a strong transcriptional response to $R$. solanacearum infection.

We utilized resistant 'Hawaii 7996' (H7996) and susceptible 'West Virginia' (WV) for our analyses. H7996 is a variety of cultivated tomato (Solanum lycopersicum) that is resistant to many different $R$. solanacearum strains (Lebeau et al. 2011). WV is an accession of $S$. pimpinellifolium, the closest wild relative to
S. lycopersicum (Tomato Genome Consortium 2012), and is highly susceptible to $R$. solanacearum. We chose these genotypes for transcriptomic analysis because they are the parents of a recombination inbred line population that has been used in multiple QTL studies (Carmeille et al. 2006; Thoquet et al. 1996a; Wang et al. 2000, 2013) for resistance to $R$. solanacearum. Transcriptomic data may be useful toward the further identification of genes underlying resistance QTL. Because resistant H7996 (S. lycopersicum) and susceptible WV (S. pimpinellifolium) are different species, we identified the response within each species by comparing each timepoint ( 24 or $48 \mathrm{hpi}$ ) to the 0 -hpi mock control for each genotype.

We hypothesized that transcriptional events that promoted defense responses in roots of resistant plants would occur early, before wilting, but would be nonexistent or diminished in roots of susceptible plants. We inoculated roots using our previously established soil-soak inoculation method (Caldwell et al. 2017), in which wilting typically begins at 72 to $96 \mathrm{hpi}$ in WV. We previously performed light and scanning electron microscopy and showed that bacteria colonize the root of both resistant $\mathrm{H} 7996$ and susceptible WV at 24 and $48 \mathrm{hpi}$ at $2.5 \mathrm{~cm}$ below the root-shoot junction (Caldwell et al. 2017). Here, we first tested whole roots to confirm that $R$. solanacearum colonizes roots of resistant H7996 and susceptible WV at 24 and 48 hpi (Fig. 1). Plants were grown in potting mix and were inoculated with $R$. solanacearum $\mathrm{K} 60$ at $10^{8} \mathrm{CFU} / \mathrm{ml}$ at the three-leaf stage as in the study by Caldwell et al. (2017). Consistent with our previous results, in three independent experiments, bacteria colonized roots of both resistant $\mathrm{H} 7996$ and susceptible WV at 24 and 48 hpi (Fig. 1). We then used genome-wide RNA-seq analysis to identify the $R$. solanacearum-responsive transcriptome of whole roots in resistant H7996 and susceptible WV tomatoes prior to the onset of wilting at 0,24 , and $48 \mathrm{hpi}$. Plants were grown and were root inoculated as above. Whole roots were harvested at 0,24 , and 48 hpi. Total RNA from 10 roots was pooled for each genotype at each timepoint and was sent to the Purdue Genomics Facility for library creation and sequencing on the Illumina HiSeq2500 (discussed below). Reads were mapped to the $S$. lycopersicum genome (ITAG2.4) by the Purdue Genomics Facility using TopHat2 version 2.0.14.

Pairwise comparisons were made between each timepoint and 0 hpi (mock-inoculated control) to identify transcriptional responses to $R$. solanacearum infection within each genotype. We

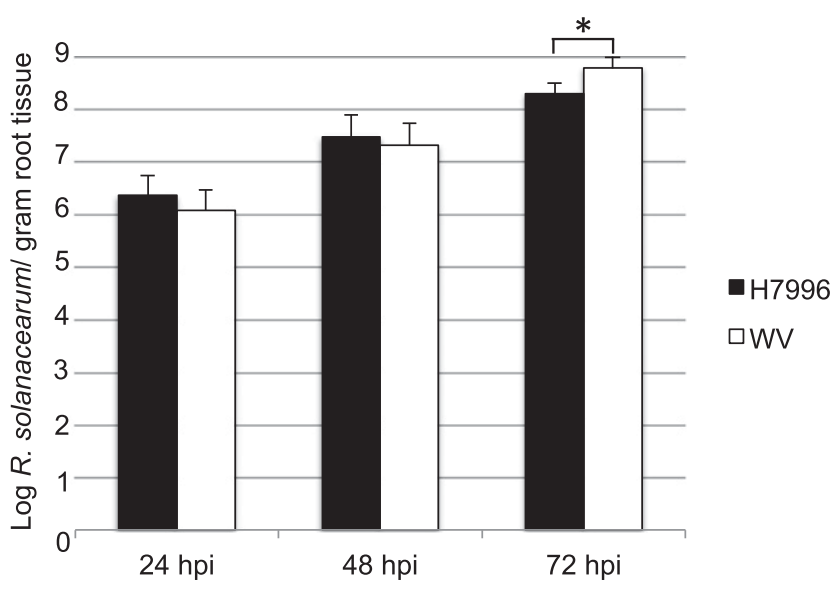

Fig. 1. Root colonization of Ralstonia solanacearum K60 in whole roots of resistant 'Hawaii 7996' and susceptible 'West Virginia' (WV). Plants were grown in potting mix and were root-inoculated via soil soaking at the threeleaf stage. The average of three independent replicates, each with roots of three plants per genotype and timepoint, is shown. Error bars indicate standard deviation. The asterisk $(*)=P<0.05$ with the Mann Whitney Wilcoxon test 
classified responsive genes (DEGs) as those that showed a $\log 2$ fold change $>|0.585|$ and a false discovery rate (FDR) $<0.05$. To understand how the response to $R$. solanacearum infection in resistant and susceptible roots differed, the DEGs at each timepoint

\begin{tabular}{|c|c|c|}
\hline \multirow{2}{*}{ Comparison } & \multicolumn{2}{|c|}{$\log 2 \mathrm{FC}>0.585, \mathrm{FDR}<0.05$} \\
\cline { 2 - 3 } & UP & DN \\
\hline WV 24-0h & 427 & 545 \\
\hline WV 48-0h & 1316 & 1571 \\
\hline Exclusive WV 24h & 92 & 165 \\
\hline Exclusive WV 48h & 594 & 808 \\
\hline H7996 24-0h & 957 & 1029 \\
\hline H7996 48-0h & 1265 & 1419 \\
\hline Exclusive H7996 24h & 622 & 649 \\
\hline Exclusive H7996 48h & 543 & 656 \\
\hline
\end{tabular}
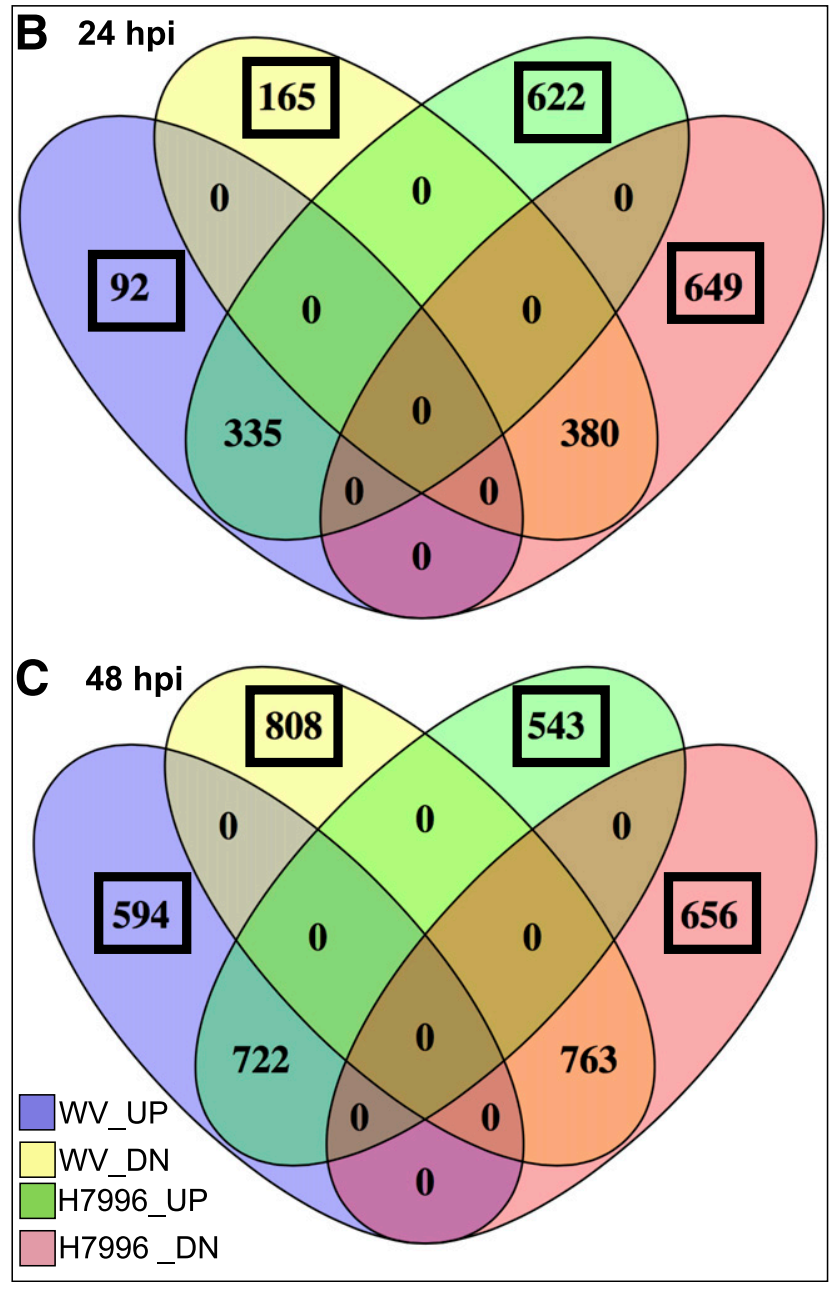

Fig. 2. Summary of differentially expressed genes (DEGs) from pairwise comparisons between timepoints within each genotype ('Hawaii 7996' and 'West Virginia' [WV]). A, Numbers of DEGs at each pairwise comparison within each genotype. Threshold for differential expression is $\log 2$ fold change $>|0.585|$, false discovery rate $<0.05$. $\mathbf{B}$ and $\mathbf{C}$, Venn diagrams of upand downregulated DEGs at 24 and $48 \mathrm{~h}$ postinoculation (hpi), respectively, showing overlap between the responses of resistant Solanum lycopersicum L. 'Hawaii 7996' (H7996) and susceptible S. pimpinellifolium WV. Boxed numbers show 'exclusive' genes at each timepoint. within a genotype were then compared between genotypes (Fig. 2) The mapping summary is in Supplementary Table S1, normalized library sizes are in Supplementary Table S2, raw counts are listed in Supplementary Table S3, and processed edgeR gene expression results are in Supplementary Table S4. Differential expression analysis showed that within susceptible roots at $24 \mathrm{hpi}, 427$ genes were upregulated and 545 were downregulated, while, within resistant roots at that timepoint, almost twice as many genes were differentially expressed (957 up and 1,029 down) (Fig. 2). At 48 hpi, 1,316 genes were upregulated in susceptible roots and 1,571 were downregulated, compared with 1,265 upregulated in resistant roots and 1,419 downregulated. We used quantitative reverse transcription-polymerase chain reaction (qRT-PCR) to validate the differential expression of 15 genes. These showed similar expression patterns as identified in our RNA-seq analysis (Supplementary Fig. S1).

At each timepoint, we also examined genes that were up- or downregulated only within resistant H7996 or susceptible WV roots (Fig. 2B and $\mathrm{C}$, boxed numbers). We call these genes 'exclusive' genes. Major shifts in numbers of exclusive DEGs were observed in susceptible roots between 24 and 48 hpi. For example, at $24 \mathrm{hpi}$, only 92 genes were exclusively upregulated in susceptible WV roots, compared with 622 genes in resistant $\mathrm{H7996}$ roots. However, by $48 \mathrm{hpi}$, this number rose to 594 genes in susceptible WV roots compared with 543 in resistant H7996 roots (Fig. 2). We did not identify any significant DEGs whose expression was upregulated in roots of resistant $\mathrm{H} 7996$ and was simultaneously downregulated in susceptible WV (or vice versa) at either timepoint.

We used GO analysis to understand what biological processes were affected within roots of resistant H7996 and susceptible WV plants after inoculation. GO analysis using PANTHER (Mi et al. 2016) showed that among the 427 upregulated genes in susceptible WV at $24 \mathrm{hpi}$, only seven GO terms for biological process are overrepresented $(P<0.05)$ (Supplementary Table S5). These include 'response to stress' (GO: 0006950; $P=9.76 \times 10^{-3}$ ) and 'response to stimulus' (GO: 0050896; $P=2 \times 10^{-2}$ ). In contrast, at 24 hpi in roots of the resistant H7996, 27 biological process GO terms were overrepresented in the 957 upregulated genes (Figure 3 shows a subset of overrepresented GO categories, including 'reactive oxygen species metabolic process' [GO:0072593; $P=6.3 \times 10^{-6}$ ] and 'cellular detoxification' [GO:1990748; $\left.P=8.7 \times 10^{-6}\right]$ ). Not unexpectedly, the GO category 'defense responses' (GO: 0006952; $P=2.45 \times 10^{-5}$ ) was identified in upregulated genes in roots of the resistant plant at 24 hpi (Fig. 3) but was not present in upregulated genes of susceptible roots at this timepoint. Among the 545 downregulated genes at 24 hpi in susceptible WV roots, 25 biological process GO terms are overrepresented, including 'plant-type cell-wall organization or biogenesis' (GO:0071669; $P=2.38 \times 10^{-2}$ ), 'reactive oxygen species metabolic process' (GO:0072593; $P=3.34 \times 10^{-3}$ ), and 'cellular detoxification' (GO:1990748; $P=1.69 \times 10^{-4}$ ) (Fig. 4). Notably, and as stated above, the latter two GO categories were both overrepresented in upregulated genes in resistant roots at this timepoint. GO overrepresentation in downregulated H7996 genes at 24 hpi included 'regulation of jasmonic acid (JA)-mediated signaling pathway' (GO:2000022; $P=1.26 \times 10^{-6}$ ) (Fig. 4), consistent with the downregulation of JA responses in resistant plants after infection with some biotrophic pathogens (Glazebrook 2005; Koornneef and Pieterse 2008; Koornneef et al. 2008; Spoel et al. 2003, 2007).

Many of the same trends in GO terms were observed at 48 as at 24 hpi in each genotype. For example, 'reactive oxygen species metabolic process' and 'cellular detoxification' categories were still overrepresented in upregulated genes in the resistant $\mathrm{H} 7996$ root at 48 hpi (Fig. 3) $\left(P=5.41 \times 10^{-5}\right.$ and $P=$ $3.47 \times 10^{-4}$, respectively) but were not overrepresented in 
upregulated genes of the susceptible WV root at either timepoint (Fig. 3). The GO category 'defense response' continued to be overrepresented in upregulated genes of the resistant H7996 root at 48 hpi $\left(P=2.98 \times 10^{-15}\right)$ (Fig. 3). While the 'defense response' category was not overrepresented at $24 \mathrm{hpi}$ in the root of susceptible WV, it was identified at 48 hpi $(P=$ $4.27 \times 10^{-20}$ ) in upregulated genes of the susceptible WV root (Fig. 3). In downregulated genes, 'cell-wall organization or biogenesis (GO:0071554)' was overrepresented in susceptible roots at $48 \mathrm{hpi}\left(P=1.46 \times 10^{-4}\right)$, while 'JA-mediated signaling pathway' continued to be overrepresented in the resistant H7996 plant at 48 hpi $\left(P=3.78 \times 10^{-3}\right)($ Fig. 4).

\section{Defense gene activation occurs earlier and is stronger in roots of resistant tomato plants.}

Our GO analysis of genes up- and downregulated at each timepoint showed that roots of resistant plants activated genes enriched for immune GO categories (such as 'response to biotic stimulus', 'response to oxidative stress', 'defense response', and 'response to stimulus') earlier in the resistant $\mathrm{H} 7996$ root than in the susceptible WV root (Figs. 3 and 4).

To examine this more carefully, we next focused on the expression of specific defense marker genes in classic defense hormone pathways. We examined genes previously used as markers for defense responses in resistant H7996 (Milling et al. 2011). The ethylene (ET) marker gene $P R-1 b$ was upregulated only in the resistant H7996 genotype, while Osmotin was activated earlier and with a higher fold change compared with 0 hpi in H7996 compared with WV (Fig. 5A). Salicylic acid
(SA) marker genes were similarly regulated, with $P R-1 a$ being exclusively activated in $\mathrm{H} 7996$ at 48 hpi, and Glu-A was activated more strongly in H7996 compared with susceptible WV at both 24 and 48 hpi.

Consistent with JA and SA antagonism (Derksen et al. 2013; Robert-Seilaniantz et al. 2011) and our GO analysis above, marker genes for JA defense responses were repressed in both resistant $\mathrm{H} 7996$ and susceptible WV but showed greater fold change repression in roots of the resistant $\mathrm{H} 7996$ plants. AOS (ALLENE OXIDE SYNTHASE) and LoXA (LIPOXYGENASE) were both downregulated in resistant $\mathrm{H} 7996$ after both timepoints. LoxA was also downregulated in WV (Fig. 5A). This corresponded to the GO enrichment analysis that showed that regulation of JA-mediated signaling was overrepresented in downregulated genes only for resistant H7996 (Fig. 4). Together, these results reveal activation of SA- and ET-dependent defense pathways earlier in roots of the resistant plant H7996 as well as an earlier deactivation of JA-dependent defense signaling in resistant $\mathrm{H} 7996$.

In addition to these classic defense pathways, we observed strong upregulation of terpene synthases (TPSs) in resistant tomato roots (Fig. 5B). Terpenoids are a large class of compounds composed of five carbon isoprene units and are building blocks of some plant hormones and of specialized secondary metabolites (Falara et al. 2011). Tomato has 44 TPS genes, of which 29 are functional and are divided into five clades (Falara et al. 2011). In roots of resistant plants, five TPS genes in the alpha clade, which encode sesquiterpene synthases (TPS28, TPS31, TPS32, TPS33, and TPS35), a TPS-like gene, and a linadool/nerolidol synthase

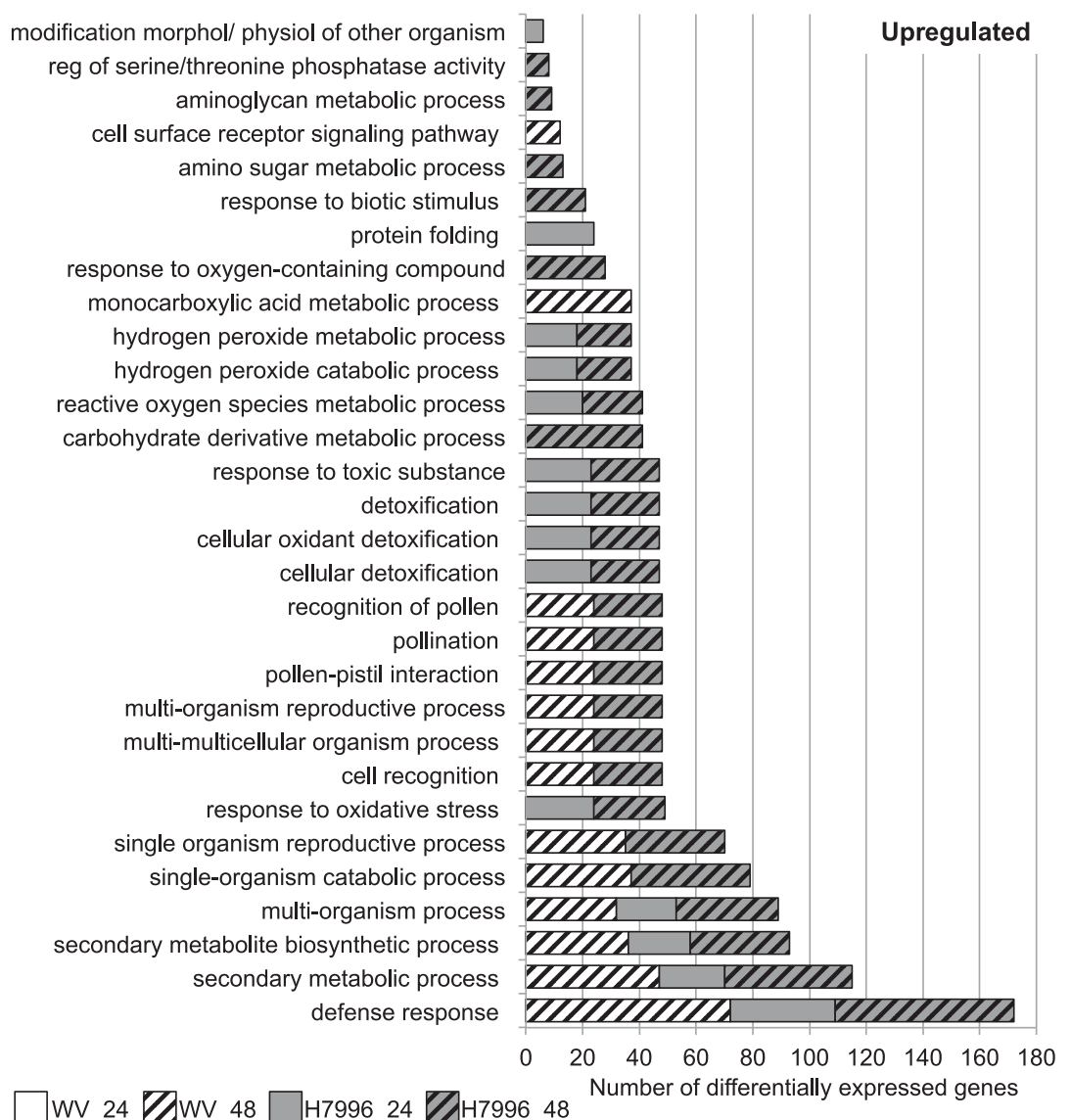

Fig. 3. Gene Ontology $(\mathrm{GO})$ categories overrepresented (corrected $P$ value $<0.05$ ) in the set of upregulated genes at each timepoint. Only categories that contain less than 600 total Solanum lycopersicum genes are shown. WV = 'West Virginia', H7996 = 'Hawaii 7996', and 24 and 48 indicate comparisons between timepoint 0 with the 24 and 48 h postinoculation timepoints, respectively. No GO categories with less than 600 total genes are overrepresented in WV_24 upregulated genes. 
(TPS39) are strongly upregulated at 24 and 48 hpi (Fig. 5B). In contrast, only one sesquiterpene synthase, TPS28, and the linadool/ nerolidol TPS39 are upregulated in susceptible roots at $48 \mathrm{hpi}$ (Fig. 5B). Terpenoids act as antimicrobial or anti-insect compounds, and the strong upregulation observed in roots of resistant plants may contribute to resistance.

\section{Roots of susceptible tomato plants downregulate genes required for organ growth at $\mathbf{4 8} \mathrm{hpi}$.}

To have a better understanding of the response within roots of each genotype, we focused on genes that were exclusively responsive within each timepoint in each genotype (i.e., genes that were activated or repressed only within $\mathrm{H} 7996$ or WV at each timepoint [Fig. 2B and C, boxed numbers]). All nine GO terms that overlapped among exclusive genes in WV and H7996 were related to defense and detoxification (Supplementary Fig. S2). Consistent with earlier and larger fold change defense responses in the resistant $\mathrm{H} 7996$ root, all but one of these categories were found both in genes upregulated in the resistant H7996 root at 24 hpi and genes downregulated in the susceptible WV root at $24 \mathrm{hpi}$.
Analysis of the 808 genes exclusively downregulated at 48 hpi in susceptible WV roots revealed several GO categories with known roles in root growth. These included GO categories 'DNA replication' (GO: 0006260; $\left.P=8.7 \times 10^{-7}\right)($ Jia et al. 2016; Ni et al. 2009), DNA packaging (GO:0006323; $P=4.4 \times 10^{-10}$ ), chromatin assembly (GO:0031497, $P=9.7 \times 10^{-11}$ ) (Aichinger et al. 2011; Sang et al. 2012; Shen and Xu 2009), and translation (GO: 0006412; $P=3.7 \times 10^{-31}$ ) (Wieckowski and Schiefelbein 2012) (Fig. 6). Genes repressed in these categories included DNA replication helicases MCM3 (Solyc02g070780), MCM4 (Solyc01g110130), MCM5 (Solyc07g005020), and MCM7 (Solyc01 g079500), ribosomal proteins, and histones. In Arabidopsis, MCM2 is involved in DNA replication and is important for root meristem maintenance $(\mathrm{Ni}$ et al. 2009) and mutations in a DNA helicase/nuclease result in very short roots (Jia et al. 2016). Further, mutation of AtMDN1, an AAA-ATPase that is a component of the pre-60S ribosome, results in several developmental defects, including a shorter root (Li et al. 2016). Histone modifications have also been shown to be critical for proper root growth and development (Takatsuka and Umeda 2015). None of these GO categories were identified within DEGs in the resistant H7996 root (Fig. 6).

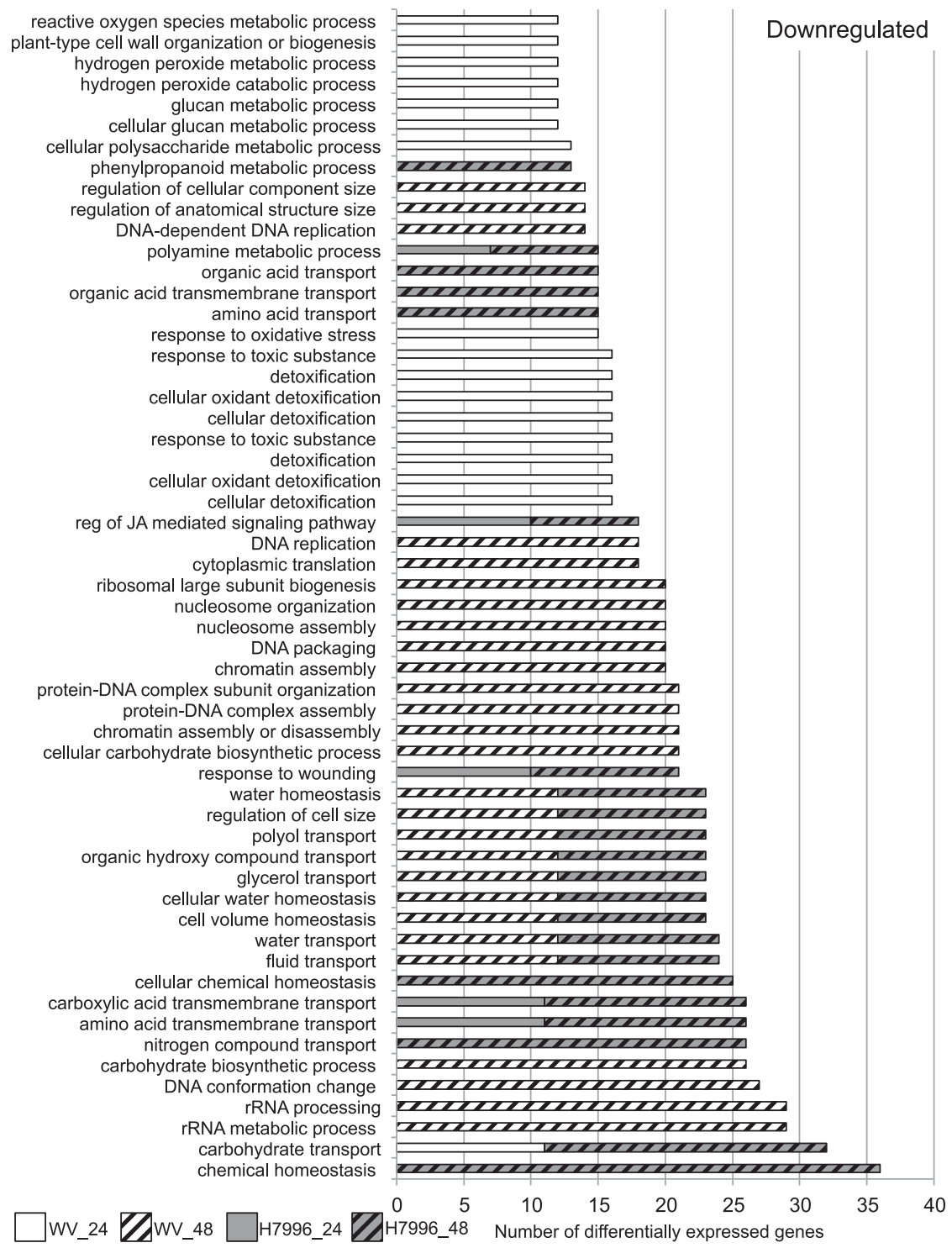

Fig. 4. Gene Ontology categories overrepresented (corrected $P$ value $<0.05$ ) in the set of downregulated genes at each timepoint. Only categories that contain less than 300 total Solanum lycopersicum genes are shown. WV = 'West Virginia', H7996 = 'Hawaii 7996', and 24 and 48 indicate comparisons between timepoint 0 with the 24 and $48 \mathrm{~h}$ postinoculation timepoints, respectively. 
These data suggested that roots of susceptible plants slow growth after infection. To test this, we quantified root growth of H7996 and WV at 10 days postinoculation (dpi). Plants were removed from pots and the root systems were gently washed with water to remove soil. Cleaned roots were scanned and the surface area quantified, using a WinRHIZO root scanning and quantification system (Arsenault et al. 1995). We found that roots of WV have significantly decreased surface area after inoculation compared with mock-inoculated controls (Fig. 7). In contrast, $R$. solanacearum-inoculated roots of resistant $\mathrm{H7996}$ have no difference in surface area compared with mockinoculated resistant roots (Fig. 7). The differential root-growth response to $R$. solanacearum between resistant and susceptible accessions is consistent with the transcriptional changes that we observed.

Consistent with the hypothesis that the susceptible WV root responds to $R$. solanacearum with growth suppression, far fewer GO categories were overrepresented in the set of exclusively upregulated genes in WV roots at $48 \mathrm{hpi}$. Three GO categories were identified among the 594 number of genes exclusively upregulated in $\mathrm{WV}$, compared with 72 categories identified among the 808 downregulated genes. Among the three GO categories overrepresented in the exclusively upregulated genes in WV at 48 hpi was 'defense response' (GO: 0006952; $P=1.01 \times$ $10^{-4}$ ). Together these results show that, although roots of the susceptible WV plant do eventually activate defense responses, they are also initiating processes that limit root growth.

\section{Auxin response pathways are altered in roots of resistant plants.}

$\mathrm{GO}$ analysis of genes that were exclusively expressed in roots of the resistant variety $\mathrm{H} 7996$ at each timepoint revealed that the categories 'auxin-activated signaling pathway' (GO:0009734; $P=4.3 \times 10^{-2}$ ) and 'cellular response to auxin stimulus' (GO: $0071365, P=4.3 \times 10^{-2}$ ) were overrepresented in genes exclusively downregulated in the resistant H7996 at 48 hpi (Fig. 8).

Examination of the eight genes within these categories identified three genes encoding transcription factors known as AUXIN RESPONSE FACTORS (ARFs), which have both positive and negative roles in auxin signaling. These included two S. lycopersicum orthologs (Solyc12g042070 and Solyc03g118290) of Arabidopsis ARF2 and the S. lycopersicum ortholog of Arabidopsis ARF4 (Solyc11g069190). Of the other five genes within the 'auxin response' GO category, one encoded a PIN auxin transporter (Solyclog080880), three were AUX/IAA transcription factors (Solyc06g008590, Solyc06g008580, Solyc01g097290), and another encoded an uncharacterized gene (Solyc02g036370) related to the REVEILLE1 transcription factor in Arabidopsis.

\section{The tomato auxin transport mutant diageotropica (dgt) is resistant to $R$. solanacearum.}

One of the genes within the auxin response GO category above was Solyclog080880, which encodes a PIN auxin efflux transporter known as SISTER OF PIN1b (SISoPIN1b). PIN proteins are the primary auxin efflux transporters in plants and are responsible for polar auxin transport (Adamowski and Friml 2015; Křček et al. 2009). In Arabidopsis, mutations in several auxin transporters, including PIN2, lead to decreased disease symptoms caused by Fusarium oxysporum (Kidd et al. 2011). We hypothesized that tomato genes required for polar auxin transport function in resistance to $R$. solanacearum. To test this, we examined resistance of the tomato mutant $d g t$ to $R$. solanacearum. $D G T$ encodes a cyclophilin that negatively regulates PIN auxin efflux transporters in tomato (Ivanchenko et al. 2015). Mutations in $D G T$ lead to altered auxin transport and changes to one or both the transcription or protein localization of PINs (Ivanchenko et al. 2015). Root inoculation of the $d g t 1-1$ mutant and its susceptible wild-type parent Ailsa Craig (AC) showed that $d g t l-1$ was highly resistant to $R$. solanacearum compared with the wild-type parent (Fig. 9). Three independent biological replicates revealed that mutant plants had approximately $10 \%$ wilting at $12 \mathrm{dpi}$. In contrast, the wild-type parent had almost $100 \%$ wilting at the same timepoint.

\section{The increased resistance of $\operatorname{dgt} 1-1$ is not due solely to alterations in root architecture.}

The dgt 1-1 mutant has been previously described as lacking lateral roots (Ivanchenko et al. 2015; Muday et al. 1995; Oh et al. 2006). Because $R$. solanacearum enters the root system in part through wounds created as lateral roots emerge from the primary root, we questioned whether the decreased wilting in dgtl-1 was due to deficiencies in lateral root emergence. Previous work showing a lack of lateral roots in $d g t 1-1$ used plants grown in agar (Ivanchenko et al. 2015). However, examination of root systems of $d g t l-1$ grown in potting mix revealed that the mutant does produce lateral roots in these conditions (Fig. 10B, arrows), although roots of $d g t 1-1$ were still significantly smaller compared with the wild-type parent AC (Fig. 10).

To examine whether the altered root structure was the underlying basis for the increased resistance, we used petiole inoculation of $R$. solanacearum in $d g t 1-1$ and the wild-type
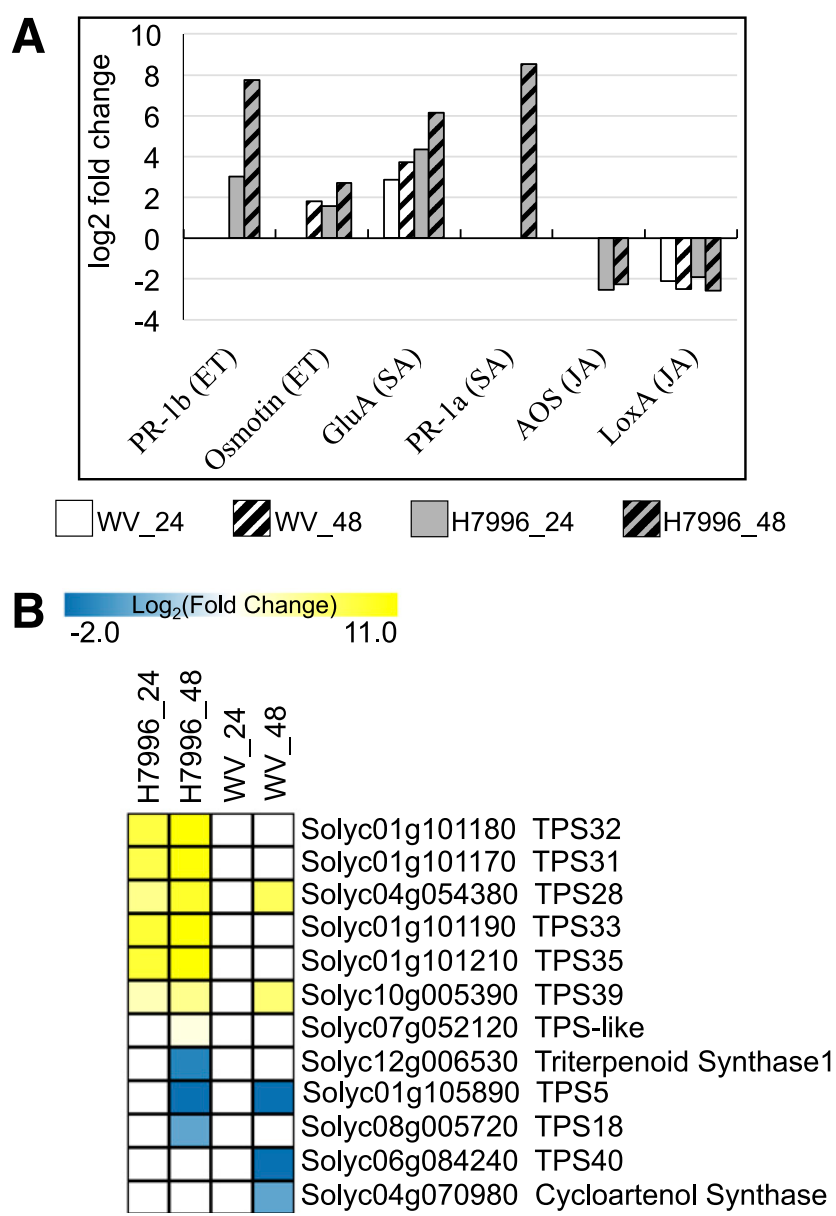

Fig. 5. Defense responses are activated earlier and with higher fold changes in the root of resistant 'Hawaii 7996' (H7996). A, Log fold changes in RNA-seq data of marker genes for classic defense hormones, B, Heat map showing log fold changes of genes in the 'terpenoid' bin in MapMan software (Thimm et al. 2004). More terpene synthase (TPS) genes are activated in roots of resistant plants and at an earlier timepoint. 
background AC. This method bypasses the root system by directly injecting bacteria into the petiole vasculature (Dalsing and Allen 2014; Tans-Kersten et al. 2001). If decreased lateral root emergence in the $d g t 1-1$ mutant were the primary reason for resistance, we would expect that the dgtl-1 mutant would show an increased susceptibility using this method. Using petiole inoculation, the dgtl-1 mutant did not wilt by $12 \mathrm{dpi}$, compared with approximately $90 \%$ wilting in the wild-type AC control (Fig. 11). Together, these results suggest that the enhanced resistance to $R$. solanacearum in the dgtl-1 mutant is due to modulation of auxin transport.

\section{DISCUSSION}

In this manuscript, we show that infection with the soilborne pathogen $R$. solanacearum leads to a strong defense response in tomato roots that includes alteration of auxin pathways. Analysis of a tomato mutant with defective auxin transport confirmed a role for auxin pathways in resistance. Susceptible tomato roots are stunted at $10 \mathrm{dpi}$, and, consistent with this, we find significant suppression of genes required for growth and cellular homeostasis at 24 and $48 \mathrm{hpi}$. Additionally, roots of the susceptible variety are slower to activate defense responses, and their defense responses are lower in magnitude compared with resistant roots.

Genome-wide transcriptional responses to $R$. solanacearum in tomato have been previously examined primarily in aboveground regions of the plant. (Ghareeb et al. 2011; Ishihara et al.
2012; Kiirika et al. 2013). Ishihara et al. (2012) used tomato microarrays to examine gene-expression changes 24 hpi with $R$. solanacearum $8107 \mathrm{~S}$ in stems and leaves of susceptible tomato 'Ponderosa' and resistant 'LS-89'. They did not identify any changes in gene expression at 24 hpi in the susceptible cultivar and only 156 genes were differentially expressed in leaves of the resistant cultivar, compared with the mock-inoculated controls. Differences in our results can be explained, in part, by the region of the plant sampled (aboveground versus belowground), inoculation method, or the result of differences in the gene expression profiling method used in each study (microarray versus RNA-seq). Despite these differences, several of the genes upregulated in resistant tomato stems were found in similar pathways as those we identified in roots of resistant H7996, including pathogenesis-related $(P R)$ genes. In line with the idea of some overlap in defense responses between below and aboveground regions to $R$. solanacearum, defense marker gene expression in aboveground regions of resistant tomato plants also occurred earlier and with a higher fold change in resistant H7996 compared with susceptible 'Bonnie Best' (Milling et al. 2011). Together, these data suggest that root defense responses partially overlap with those in the shoot but also have unique responses to pathogen attack.

We observed a strong upregulation of TPS genes specifically in roots of resistant plants. Analysis of ginger leaves after rhizome infection with $R$. solanacearum revealed a similar upregulation of TPSs in resistant plants (Prasath et al. 2014). A previous report (Lin et al. 2014) used virus-induced gene

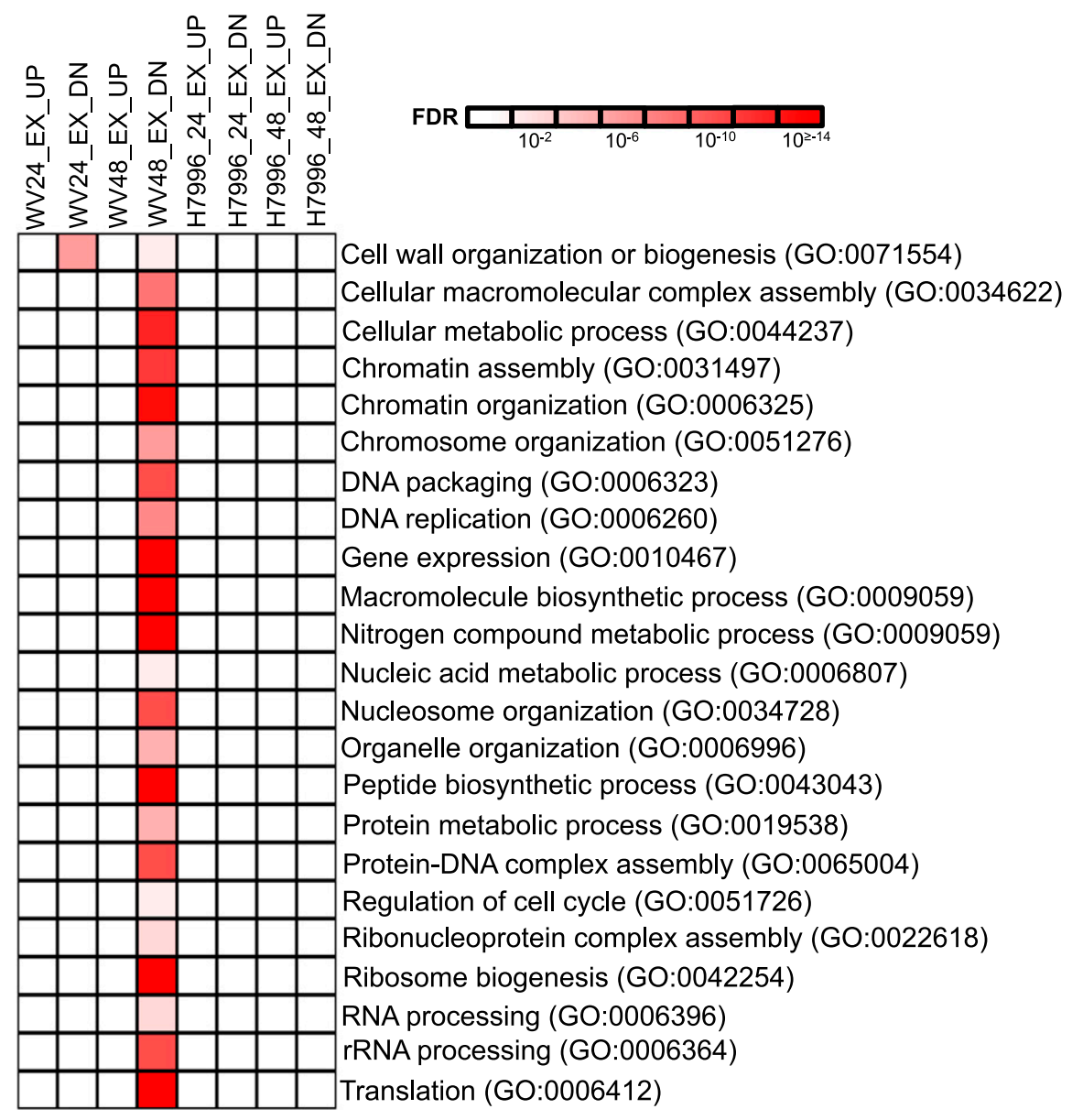

Fig. 6. Roots of susceptible plants strongly repress pathways required for organ growth at $48 \mathrm{~h}$ postinoculation (hpi). Heatmap of selected overrepresented Gene Ontology (GO) categories (corrected $P<0.05$ ) in up- and downregulated genes in roots of susceptible 'West Virginia 799' (WV) and 'Hawaii 7996' (H7996) at 24 and 48 hpi. No overrepresented categories were observed in WV24_EX_UP. 
silencing in resistant $\mathrm{H} 7996$ to knock down expression of four TPS genes (TPS31, TPS32, TPS33, and TPS35) that were highly upregulated in our dataset. They found that more silenced plants were colonized by $R$. solanacearum in the stem, suggesting that TPS-silenced lines had decreased tolerance to $R$. solanacearum. These data suggest that upregulation of TPS genes may contribute to resistance in tomato and ginger. However, this does not appear to be a mechanism used in all crops, as in peanut, terpenoid synthase genes were downregulated at $12 \mathrm{hpi}$ after infection in both resistant and susceptible genotypes (Chen et al. 2014). Indeed, resistance in peanut may operate through different mechanisms than in tomato, as evidenced in the root of a resistant peanut genotype in which many nucleotide binding site-LRR type resistance genes and genes encoding proteins with a LRR-receptor-like protein kinase motif were mainly downregulated at 12, 24, and 48 hpi (Chen et al. 2014).

Our data show both commonalities and differences in resistance between tomato variety $\mathrm{H} 7996$ and wild potato species S. commersonii (Zuluaga et al. 2015). In resistant roots of both species, more genes with roles in biotic stress were upregulated than downregulated. However, in contrast to our results, which found overrepresentation of the JA pathway in downregulated genes of resistant roots, no genes in the JA GO category were downregulated in roots of resistant potato plants (Zuluaga et al. 2015). Additionally, in resistant wild potato roots, genes in the auxin pathway were upregulated and none were repressed (Zuluaga et al. 2015), while we observed overrepresentation of auxin pathways in downregulated genes in resistant tomato roots. These differences could be the result of differences in species or in time of inoculation, as we sampled our plants at an earlier timepoint (24 and 48 hpi compared with 3 to 4 days).

Suppression of auxin biosynthesis, responses, and signaling has been associated with plant resistance to biotrophic or hemibiotrophic pathogens in multiple pathosystems (Fu and Wang 2011; LudwigMüller 2015)). In Arabidopsis, mutations in several auxin transporters, including PIN2 and $A U X 1$, reduce disease severity caused by the pathogenic fungus Fusarium oxysporum (Kidd et al. 2011). The watl mutant of Arabidopsis is resistant to $R$. solanacearum, has decreased auxin content in roots, suppressed indole metabolism, and decreased tryptophan in roots at 4 dpi (Denance et al. 2012). WAT1 encodes a vacuolar auxin transporter (Ranocha et al. 2013) and appears to modulate both cellular auxin levels within the vascular tissues as well as whole organ levels of auxin in the root and stem. Intriguingly, watl is resistant to multiple pathogens that, like $R$. solanacearum, colonize the vasculature but is not resistant to nonvascular pathogens such as Pseudomonas syringae pv. tomato (Denance et al. 2012). Resistance to $R$. solanacearum was dependent on SA, because watl NahG plants showed comparable levels of disease to wild-type Arabidopsis. The watl mutant was first identified due to a defect in secondary cell-wall biosynthesis (Ranocha et al. 2010). Mutations in genes required for secondary cell-wall formation, including CESA4/IRX5 (CELLULOSE SYNTHASE4/IRREGULAR XYLEM5), CESA7/IRX3, and CESA8/ $I R X 1$, also lead to enhanced resistance to $R$. solanacearum in Arabidopsis (Hernández-Blanco et al. 2007). However, in these mutants, resistance is independent of the SA pathway but dependent on abscisic acid responses (Hernández-Blanco et al. 2007).

Here, we showed that genes in auxin pathways, including SlSoPIN1b, a homolog of the PIN1 auxin transporter, are overrepresented in exclusively downregulated genes in resistant tomato roots after $R$. solanacearum infection. We find that a tomato mutant with altered auxin transport is resistant to $R$. solanacearum. Mutations in tomato DGT lead to changes in polar auxin transport that result in abnormal auxin distribution along the root (Ivanchenko et al. 2006). Polar auxin transport is crucial for plant development and is mediated by PIN auxin transporters (Adamowski and Friml 2015; Křeček et al. 2009). Roots are composed of multiple cell types and tissues that differ in auxin levels (Petersson et al. 2009). In Arabidopsis, most PIN transporters localize to the plasma membrane on specific faces of the cell, and their localization varies depending on root cell type (Blilou et al. 2005). The tomato DGT protein regulates levels and localization of PIN1 and PIN2 transporters in the root (Ivanchenko et al. 2015). In wildtype tomato roots, PIN1 localizes to the rootward face of cells in the root stele (Ivanchenko et al. 2015). The $d g t$ mutation leads to decreased PIN1 protein in the stele of root tips. In addition, expression of PIN2 is significantly decreased in root tips of the $d g t$ mutant and the PIN2 protein localization is altered (Ivanchenko et al. 2015). Although auxin levels in whole roots of the $d g t$ mutant are greater than those in wild-type plants (Ivanchenko et al. 2006), auxin responses and signaling in the root vasculature are decreased (Ivanchenko et al. 2015) due to the altered localization of PIN1 and PIN2. How mutations in DGT lead to resistance is not entirely clear. It is possible that resistance is due to indirect effects of defective auxin transport and not directly due to auxin. Auxin plays a major role in vasculature development, and in addition to modified root architecture and other auxin-related
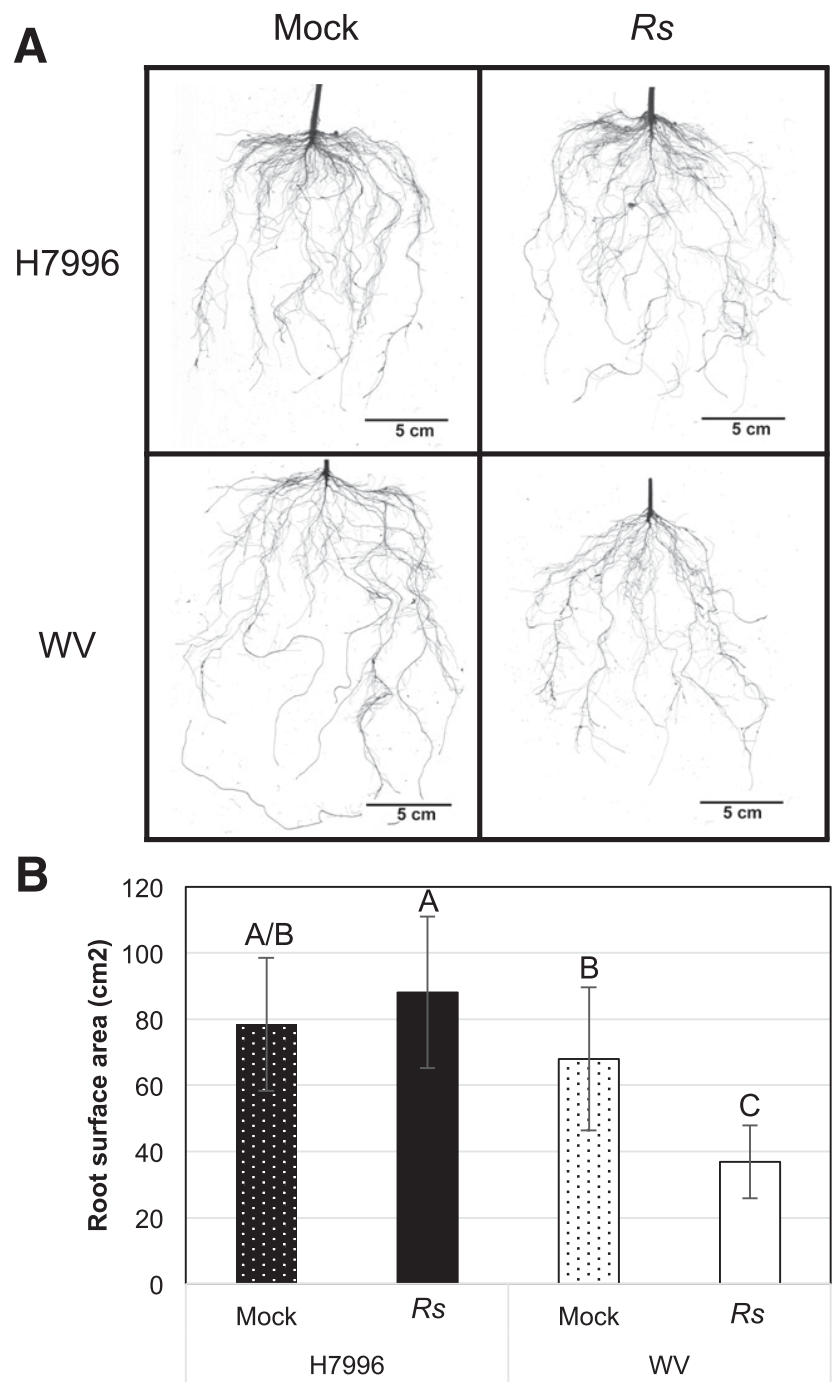

Fig. 7. Root architecture of resistant 'Hawaii 7996' and susceptible 'West Virginia' (WV) at 10 days postinoculation (dpi). A, Ralstonia solanacearum $(R s)$ and mock-inoculated roots at $10 \mathrm{dpi}$, imaged with a flatbed scanner. Representative images from three independent experiments, each with at least five roots per genotype and treatment, are shown, B, Quantification of whole root surface area using the WinRHIZO software image analysis system (Arsenault et al. 1995). Letters indicate significant differences $(P<0.05)$ with a two-way analysis of variance and Tukey's honest significant differences test. 
phenotypes, the $d g t$ mutant has altered vascular anatomy with smaller xylem vessels (Spiegelman et al. 2017; Zobel, 1974). It is possible that this altered vasculature contributes to resistance. Alternatively, resistance may be due to antagonism between auxin and SA. An additional possibility is that, like watl and other Arabidopsis mutants, dgt may have altered secondary cell-wall structure that enhances resistance.

Understanding mechanisms of root-mediated resistance is an important step in developing crops with resistance to soilborne pathogens. Like many other bacterial pathogens, $R$. solanacearum likely produces auxin (Valls et al. 2006). Whether resistant plants downregulate auxin pathways to overcome pathogen auxin production and whether the alteration of auxin transport is a general feature of root-mediated resistance are intriguing questions whose answers may lead to new insights into enhancing crop resistance.

\section{MATERIALS AND METHODS}

\section{Plant growth and $R$. solanacearum K60 inoculation.}

Resistant tomato (Solanum lycopersicum L.) accession Hawaii7996 (H7996), susceptible S. pimpinellifolium West Virginia 700 (WV), diageotropica (dgt1-1; S. lycopersicum), and AC (S. lycopersicum) were grown in Propagation Mix (Sun Gro Horticulture) in square pots containing 25 to $27 \mathrm{~g}$ of soil, under a 16-h light and 8-h dark cycle and at 28 to $30^{\circ} \mathrm{C}$ in a growth chamber. The dgtl-1 mutant has been previously reported (Oh et al. 2006), and we confirmed that the mutation was present by sequencing the gene. Growth and inoculation of $R$. solanacearum was as described by Caldwell et al. (2017). Briefly, R. solanacearum K60 (phylotype IIA, sequevar 7) was recovered from a glycerol stock and was grown for 2 days on casamino peptone agar (CPG) containing $1 \%$ triphenyltetrazolium chloride (TZC) at $28^{\circ} \mathrm{C}$. Bacteria were harvested with sterile water and were resuspended to $1.0 \times 10^{8}$ $\mathrm{CFU} / \mathrm{ml}$. At the three-leaf stage (approximately 14 to 17 days after planting), tomato plants were root-inoculated by gently lifting plants from their growth containers and, then, soaking in either inoculum or water to the root-shoot soil line (approximately $40 \mathrm{ml}$ per plant), as described by Caldwell et al. (2017). After soaking for $5 \mathrm{~min}$, seedlings were transferred back to their growth containers and were placed back into a growth chamber with the conditions above. Dilution plating was used to confirm the concentration of inoculum after each set of inoculations.

For petiole inoculation, plants and $R$. solanacearum were grown as above. At the three-leaf stage, the petiole of the first true leaf of each tomato plant was cut approximately $1 \mathrm{~cm}$ from the stem. Two microliters of inoculum at approximately $5 \times 10^{6}$ $\mathrm{CFU} / \mathrm{ml}$ was placed on the cut site with a pipette and was allowed to enter into the petiole.

For $d g t$ and $\mathrm{AC}$ resistance tests, wilting was rated daily and was scored as the percentage of leaves per plant wilted. For each soil-soak and petiole inoculation, average wilting with standard deviation are shown for three independent experiments. For soil-soak inoculation, each independent experiment had eight or nine plants per genotype, and for petiole inoculation, each experiment had from three to nine plants per genotype. The area under the disease progress curve (AUDPC)

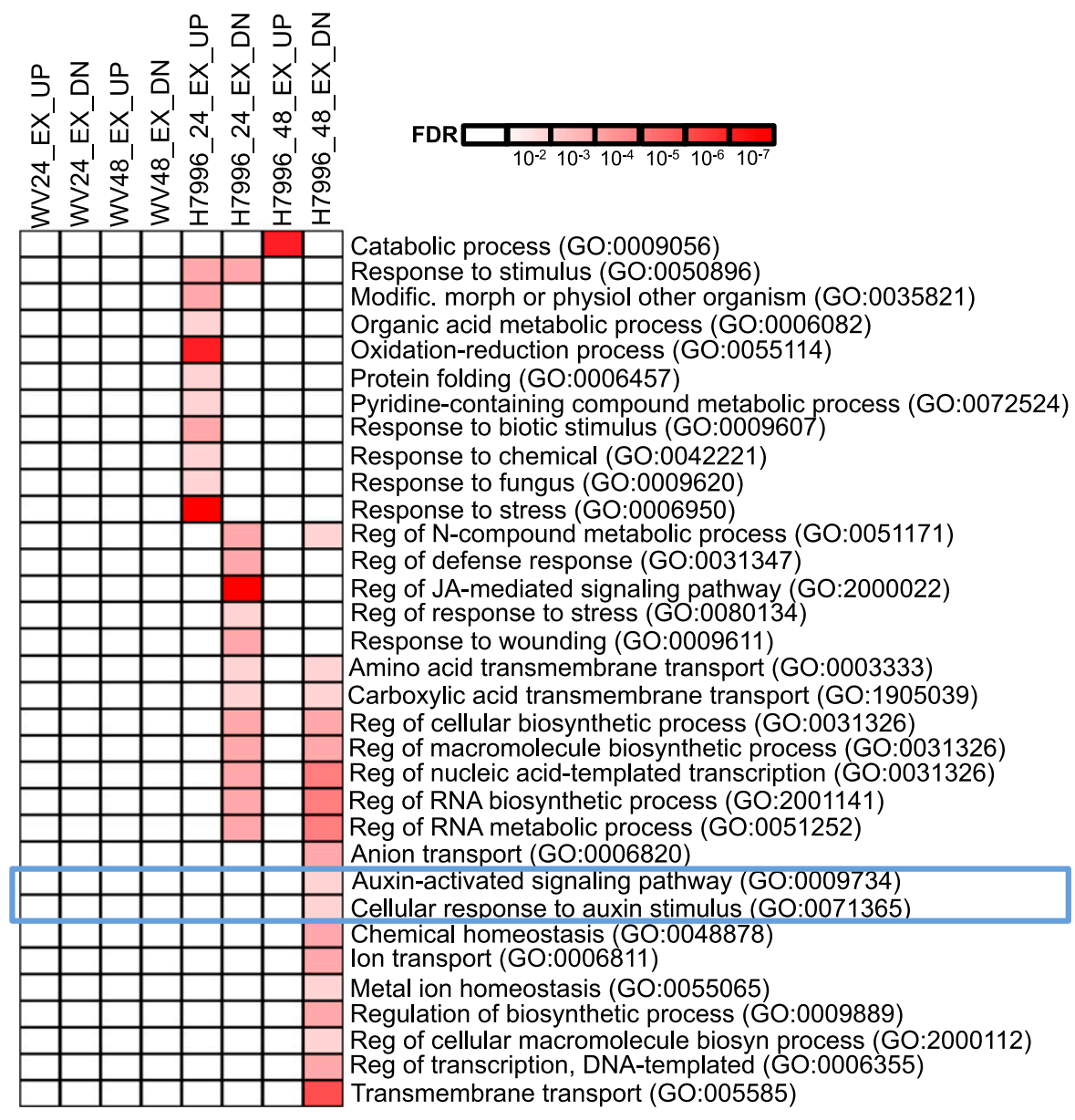

Fig. 8. Auxin-related and lateral root development genes are differentially expressed in the resistant root at $48 \mathrm{~h}$ postinoculation. Selected Gene Ontology (GO) categories overrepresented among genes exclusively differentially expressed in 'Hawaii 7996' (H7996) at each of the timepoints shown. The blue box highlights auxin-related GO categories. The nine categories that overlapped between H7996 and susceptible 'West Virginia' (WV) are not shown here. 
was calculated according to (Madden et al. 2007) with percent leaf wilting used as the disease measure.

\section{Plant colonization assays.}

Individual plants from both mock and $R$. solanacearum inoculations were removed from pots and were cut at the rootshoot junction and the soil was gently washed from roots in a tray of sterilized distilled water. Roots of each plant were transferred into a 50-ml Falcon tube containing $45 \mathrm{ml}$ of sterilized distilled water and were further cleaned to remove residual soil by shaking the Falcon tube for $1 \mathrm{~min}$. This wash was repeated five times. Water from cleaned roots was removed with a dry paper towel and roots were weighed. Washed, cleaned roots were surface sterilized by dipping in $100 \%$ ethanol for $30 \mathrm{~s}$ and were then flamed quickly to remove residual ethanol. Each surface-sterilized root was ground in $1 \mathrm{ml}$ of double-distilled (dd) $\mathrm{H}_{2} \mathrm{O}$ with a mortar and pestle, the lysate was centrifuged briefly, and the supernatant was used to determine the $R$. solanacearum K60 titer with serial dilutions in $\mathrm{ddH}_{2} \mathrm{O}$. Diluent $(100 \mu \mathrm{l})$ was plated on CPG plates containing $1 \%$ TZC and was incubated at $28^{\circ} \mathrm{C}$ for $48 \mathrm{~h}$. Colonies were counted and $R$. solanacearum $\mathrm{K} 60$ titer was determined as colony-forming units per gram of tissue. Colonization assays were performed in three independent experiments with three plants per genotype and timepoint per experiment. Data did not meet the assumption of normality and the Mann Whitney Wilcoxon test was performed in R Studio version 0.99.484.

\section{Total RNA extraction and RNA-seq sample preparation.}

Whole roots from 10 plants of each genotype (H7996 and $\mathrm{WV})$ were harvested at each timepoint $(0 \mathrm{~h}$ mock-inoculation and 24 and $48 \mathrm{hpi}$ ). Roots from these 10 plants were pooled for each genotype at each timepoint in each replicate. Three independent replicates were performed. Samples were ground into a powder using a mortar and pestle under liquid nitrogen. Ground root tissue $(100 \mathrm{mg})$ from each sample was used for total RNA extraction, using Trizol, following the manufacturer's instructions (Invitrogen). Extracted total RNA $(50 \mu \mathrm{g})$

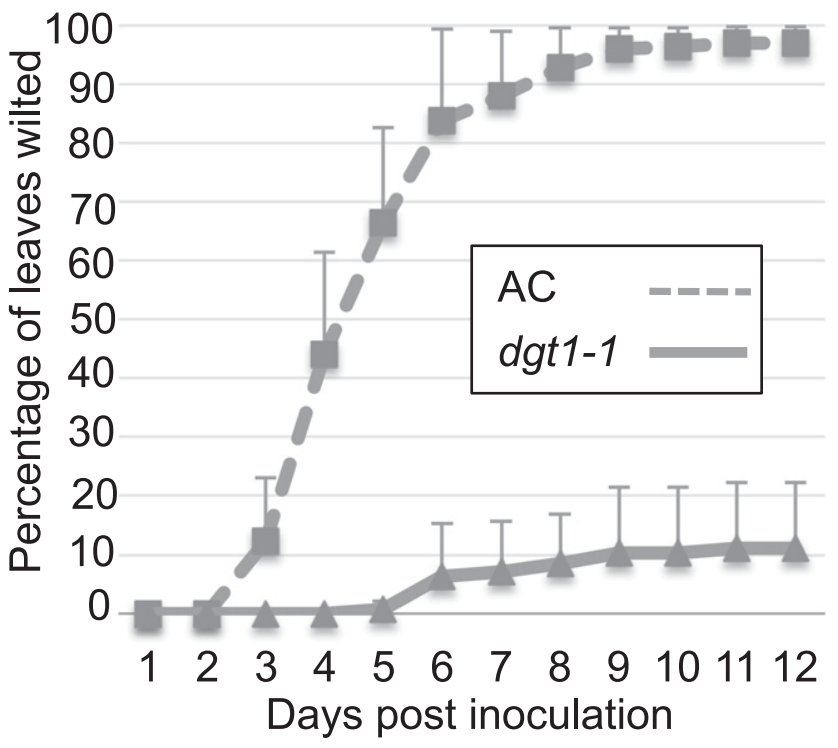

Fig. 9. The dgt1-1 mutant shows enhanced resistance to Ralstonia solanacearum compared with its wild-type control Ailsa Craig (AC) with rootsoaking inoculation. Wilting was scored daily based on the percentage of leaves wilted per plant. Each point represents the average of three independent experiments, each with eight to nine plants per genotype. The area under the disease progress curve for $\mathrm{AC}=725.2 \pm 85.2$ and for $\operatorname{dgt} 1-1=60 \pm$ $64.2(P<0.001$ with a two-tailed $t$ test $)$. Error bars indicate standard deviation. was subjected to RNAse-free DNase (Omega) treatment. DNasetreated total RNA was further cleaned, using a Nortek column, following the manufacturer's instructions (Norgen BioTek Corp). Two micrograms from each of 18 samples (three timepoints $\times$ two genotypes $x$ three replicates) were submitted to the Purdue Genomic Center for RNA-seq on the Illumina HiSeq 2500. RNA quality was determined using an Agilent Nanochip (Agilent), and all samples had a RNA integrity number of at least 7.8. Stranded mRNA libraries were constructed at the Purdue Genomics Facility, using Illumina's TruSeq stranded mRNA sample preparation kit (Revision E, Oct 2013), according to the manufacturer's instructions.

\section{RNA-seq data analysis.}

Illumina paired-end 100-bp RNA sequencing was performed on all samples. A total of 967,730,337 reads were generated after quality filtering and mapping. Reads for each of the 18 samples were aligned by the Purdue Genomics Facility to the ITAG2.4 S. lycopersicum reference genome using Tophat2 version 2.0.14 (Trapnell et al. 2009). Library type was set to strand-specific (first strand), mate inner distribution to 300, and

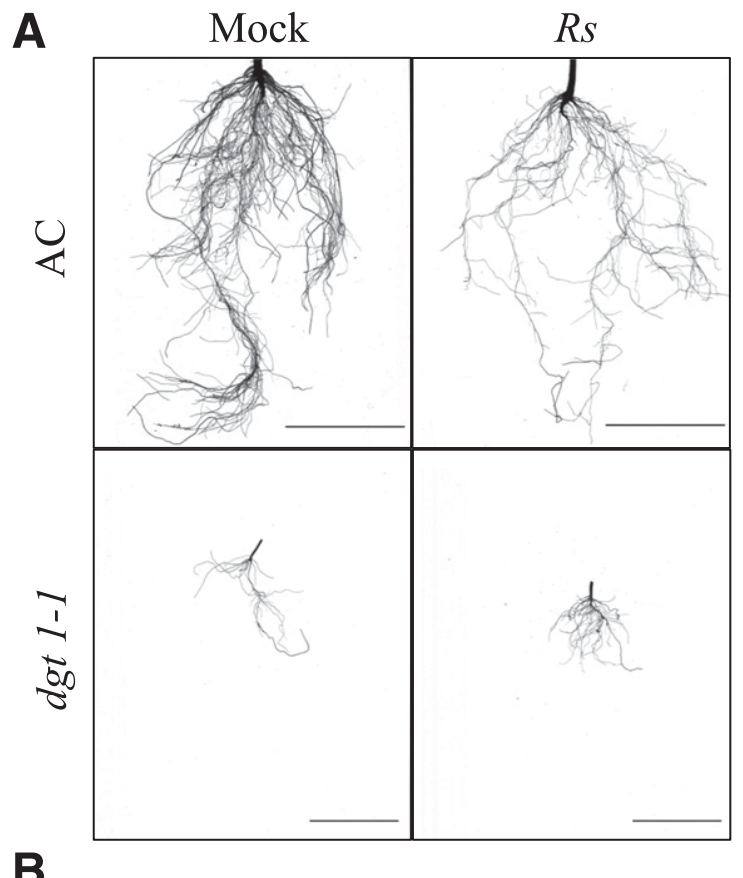

B

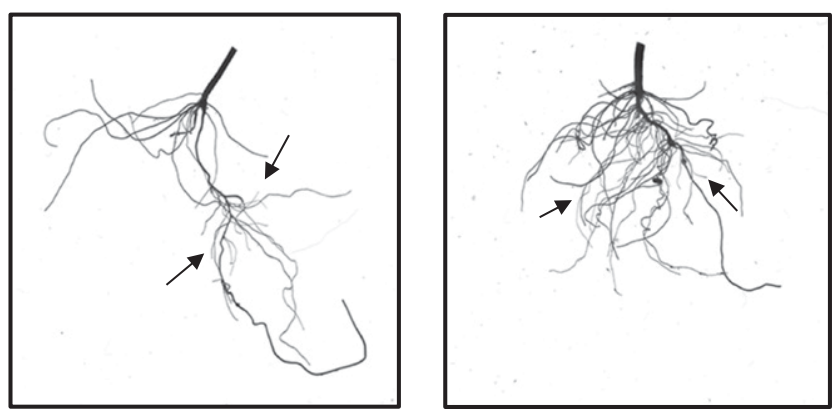

Fig. 10. Root architecture of susceptible Ailsa Craig (AC) and resistant dgt1-1, at 6 days postinoculation, grown in potting mix and soil soakinoculated with either water (mock) or Ralstonia solancearum K60 (Rs). A, Plants were grown in potting mix and roots were imaged with a flatbed scanner, B, Close-up images of dgt1-1 plants shown in A. Arrows point to examples of lateral roots. Images are representative of those from two independent biological replicates with six plants per replicate per treatment and genotype. Scale bars $=5 \mathrm{~cm}$. 
mate standard deviation to 150 . Gene expression was measured as the total number of reads for each sample that uniquely mapped to the reference, binned by gene. Each sample averaged about 54 million high-quality, uniquely aligned reads. After filtering for low counts such that at least three of the 18 samples had at least three counts per million per row, a total of 20,641 genes remained for differential expression analysis. Differential gene expression analysis was performed using the edgeR package (Robinson et al. 2010) in Bioconductor version 3.3. The edgeR function calcNormFactors was used for library normalization with the default edgeR trimmed mean of $M$ values method. DEGs were identified using the glm (general linear model) pipeline in edgeR according to the edgeR documentation. The design matrix was created with coefficients for the expression level of each group. A group consisted of genotype and timepoint (e.g., H7996_0 h = group 1, H7996_24 h = group 2). Common and tagwise dispersions were estimated with the estimateDisp function. Multidimensional scaling (MDS) analysis revealed no batch effect of different replicates (Supplementary Fig. S3). Pairwise comparisons were performed between mock $0 \mathrm{~h}$ and $24 \mathrm{hpi}$, and between mock $0 \mathrm{~h}$ and 48 hpi within each $\mathrm{H} 7996$ and WV, using the contrast argument in the glmLRT function. Differential expression was determined using the Benjamini-Hochberg FDR multiple testing correction (Benjamini and Hochberg 1995) with an adjusted $P$ value of 0.05 and a $\log 2$ fold change $>|0.585|$ (corresponds to a fold change of $>$ |1.5|). Venn diagrams were generated using VENNY 2.1 (Oliveros 2007-2015). GO analysis was performed using the PANTHER $\mathrm{GO}$ analysis tool (Mi et al. 2016). GO terms are derived from annotations of the sequenced S. lycopersicum genome Heinz1706 (Tomato Genome Consortium 2012). All GO categories shown are for 'biological process'. Heat maps, including those for GO figures were visualized with the Multiple Experiment Viewer from TM4 (Saeed et al. 2003, 2006).

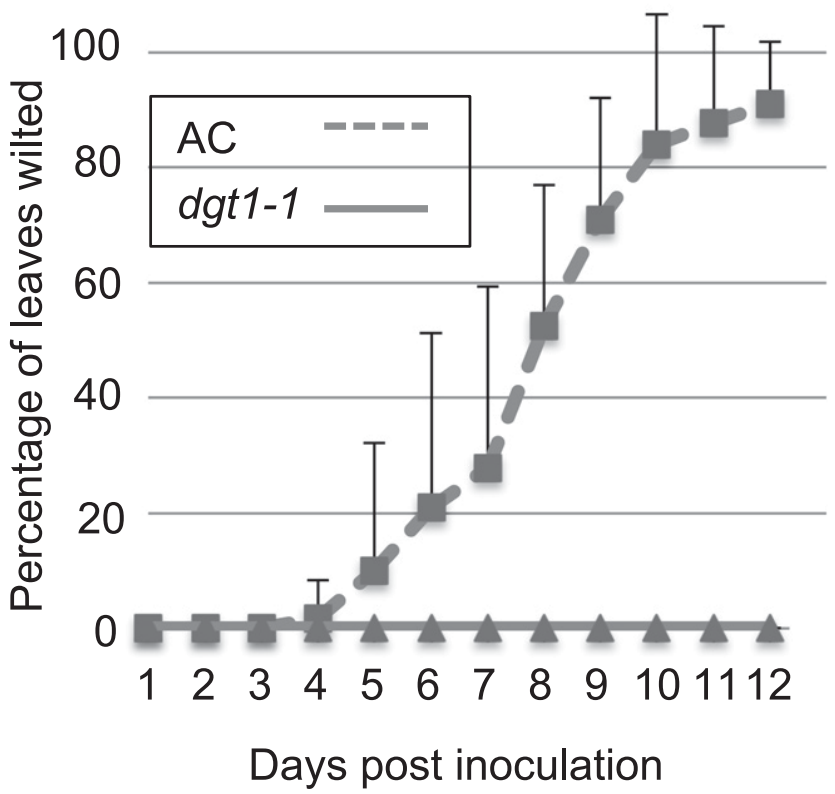

Fig. 11. The dgt1-1 mutant shows enhanced resistance to Ralstonia solanacearum compared with its wild-type susceptible parent Ailsa Craig (AC) with petiole inoculation. Wilting was scored daily based on the percentage of leaves wilted per plant. The experiment was repeated three times with three to nine plants of each genotype per experiment. The average of three experiments is shown. The average area under the disease progress curve for $\mathrm{AC}=401.6 \pm 154.8$; average AUDPC for $d g t 1-1=0 \pm 0(P<0.01$; two-tailed $t$ test with unequal variance). Error bars represent standard deviation.

\section{cDNA synthesis and qRT-PCR.}

Total RNA extraction was performed as above from root tissue used in the RNA-seq analysis. cDNA synthesis and qRTPCR was performed as described by Kim et al. (2017). Two biological replicates were used for validation. Briefly, cDNA was reverse-transcribed from $1 \mu \mathrm{g}$ of RNA, using the NEB AMV first-strand cDNA synthesis kit, as per manufacturer instructions. qRT-PCR was performed with $1 \mu \mathrm{l}$ of cDNA on a Roche light cycler (Roche), with the following amplification protocol: $50^{\circ} \mathrm{C}$ for $2 \mathrm{~min}$ and $95^{\circ} \mathrm{C}$ for $2 \mathrm{~min}$, followed by 40 cycles of $95^{\circ} \mathrm{C}$ for $15 \mathrm{~s}$ and $60^{\circ} \mathrm{C}$ for $1 \mathrm{~min}$. PCR efficiency of the primers ranged from 95 to 105\%. ACTIN (Solyc11g005330) was used as the gene for normalization. Solycl1g005330 was not differentially expressed in either $\mathrm{H} 7996$ or WV at either timepoint. The $\Delta \Delta \mathrm{Ct}$ method (Livak and Schmittgen 2001) was used to calculate fold changes relative to the internal control and the mock-inoculated control plant. Primer sequences are listed in Supplementary Table S6.

\section{Root architecture measurements.}

Roots were harvested from mock and $R$. solanacearuminoculated plants at 6 (AC and dgt1-1) or $10 \mathrm{dpi}$ (WV and H7996). Whole root systems were washed gently in water and were scanned with a calibrated color optical scanner from Regent Instruments, Inc. and were measured using software in the WinRHIZO V. 2016a system (Regent Instruments Inc.) (Arsenault et al. 1995). Data were analyzed with a two-way analysis of variance, followed by posthoc Tukey's honest significant differences test using RStudio version 0.99.484. No transformations were necessary to meet the homogeneity of variance and normality assumptions. Two independent biological replicates with at least six plants per treatment and genotype were performed for AC and dgt1-1. Three independent biological replicates with at least five roots per treatment and genotype were performed for WV and H7996. Representative images are shown.

\section{ACKNOWLEDGMENTS}

We thank M. Ivanchenko for the $d g t$ mutant, E. Sparks and members of the Iyer-Pascuzzi lab for comments on the manuscript, and P. Pascuzzi for helpful comments on RNA-seq analysis. This work was funded by a grant from the Foundation for Food and Agriculture Research, start-up funds from Purdue University, and Hatch funds to A. Iyer-Pascuzzi and a National Science Foundation Graduate Research Fellowship DGE-1333468 (to E. French).

\section{LITERATURE CITED}

Adamowski, M., and Friml, J. 2015. PIN-dependent auxin transport: Action, regulation, and evolution. Plant Cell 27:20-32.

Aichinger, E., Villar, C. B., Di Mambro, R., Sabatini, S., and Köhler, C. 2011. The CHD3 chromatin remodeler PICKLE and polycomb group proteins antagonistically regulate meristem activity in the Arabidopsis root. Plant Cell 23:1047-1060.

Arsenault, J.-L., Pouleur, S., Messier, C., and Guay, R. 1995. WinRHIZO, a root-measuring system with a unique overlap correction method. HortScience 30:906.

Benjamini, Y., and Hochberg, Y. 1995. Controlling the false discovery rate: A practical and powerful approach to multiple testing. J. R. Stat. Soc. Ser. B Met. 57:289-300.

Blilou, I., Xu, J., Wildwater, M., Willemsen, V., Paponov, I., Friml, J., Heidstra, R., Aida, M., Palme, K., and Scheres, B. 2005. The PIN auxin efflux facilitator network controls growth and patterning in Arabidopsis roots. Nature 433:39-44.

Caldwell, D., Kim, B. S., and Iyer-Pascuzzi, A. S. 2017. Ralstonia solanacearum differentially colonizes roots of resistant and susceptible tomato plants. Phytopathology 107:528-536.

Carmeille, A., Caranta, C., Dintinger, J., Prior, P., Luisetti, J., and Besse, P. 2006. Identification of QTLs for Ralstonia solanacearum race 3-phylotype II resistance in tomato. Theor. Appl. Genet. 113:110-121.

Chen, Y., Ren, X., Zhou, X., Huang, L., Yan, L., Lei, Y., Liao, B., Huang, J., Huang, S., Wei, W., and Jiang, H. 2014. Dynamics in the resistant and 
susceptible peanut (Arachis hypogaea L.) root transcriptome on infection with the Ralstonia solanacearum. BMC Genomics 15:1078.

Chen, Z., Agnew, J. L., Cohen, J. D., He, P., Shan, L., Sheen, J., and Kunkel, B. N. 2007. Pseudomonas syringae type III effector AvrRpt2 alters Arabidopsis thaliana auxin physiology. Proc. Natl. Acad. Sci. U.S.A. 104:20131-20136.

Cui, F., Wu, S., Sun, W., Coaker, G., Kunkel, B., He, P., and Shan, L. 2013. The Pseudomonas syringae type III effector AvrRpt 2 promotes pathogen virulence via stimulating Arabidopsis auxin/indole acetic acid protein turnover. Plant Physiol. 162:1018-1029.

Dalsing, B. L., and Allen, C. 2014. Nitrate assimilation contributes to Ralstonia solanacearum root attachment, stem colonization, and virulence. J. Bacteriol. 196:949-960.

Danesh, D., Aarons, S., McGill, G. E., and Young, N. D. 1994. Genetic dissection of oligogenic resistance to bacterial wilt in tomato. Mol Plant-Microbe Interact. 7:464-471.

Denance, N., Ranocha, P., Oria, N., Barlet, X., Riviere, M.P., Yadeta, K.A., Hoffmann, L., Perreau, F., Clement, G., Maia-Grondard, A., van den Berg, G.C., Savelli, B., Fournier, S., Aubert, Y., Pelletier, S., Thomma, B.P., Molina, A., Jouanin, L., Marco, Y., and Goffner, D. 2012. Arabidopsis watl (walls are thin1)-mediated resistance to the bacterial vascular pathogen, Ralstonia solanacearum, is accompanied by crossregulation of salicylic acid and tryptophan metabolism. Plant J. 73: 225-239.

Derksen, H., Rampitsch, C., and Daayf, F. 2013. Signaling cross-talk in plant disease resistance. Plant Sci. 207:79-87.

Ding, X., Cao, Y., Huang, L., Zhao, J., Xu, C., Li, X., and Wang, S. 2008. Activation of the indole-3-acetic acid-amido synthetase GH3-8 suppresses expansin expression and promotes salicylate- and jasmonateindependent basal immunity in rice. Plant Cell 20:228-240.

Falara, V., Akhtar, T. A., Nguyen, T. T., Spyropoulou, E. A., Bleeker, P. M., Schauvinhold, I., Matsuba, Y., Bonini, M. E., Schilmiller, A. L., Last, R. L., Schuurink, R. C., and Pichersky, E. 2011. The tomato terpene synthase gene family. Plant Physiol. 157:770-789.

$\mathrm{Fu}$, J., and Wang, S. 2011. Insights into auxin signaling in plant-pathogen interactions. Front. Plant Sci. 2:74

Genin, S. 2010. Molecular traits controlling host range and adaptation to plants in Ralstonia solanacearum. New Phytol. 187:920-928.

Genin, S., and Denny, T. P. 2012. Pathogenomics of the Ralstonia solanacearum species complex. Annu. Rev. Phytopathol. 50:67-89.

Ghareeb, H., Bozso, Z., Ott, P. G., Repenning, C., Stahl, F., and Wydra, K. 2011. Transcriptome of silicon-induced resistance against Ralstonia solanaceaerum in the silicon non-accumulator tomato implicates priming effect. Physiol. Mol. Plant Pathol. 75:83-89.

Glazebrook, J. 2005. Contrasting mechanisms of defense against biotrophic and necrotrophic pathogens. Annu. Rev. Phytopathol. 43:205-227.

Goverse, A., and Smant, G. 2014. The activation and suppression of plant innate immunity by parasitic nematodes. Annu. Rev. Phytopathol. 52: 243-265.

Hayward, A. C. 1991. Biology and epidemiology of bacterial wilt caused by Pseudomonas solanacearum. Annu. Rev. Phytopathol. 29:65-87.

Hernández-Blanco, C., Feng, D. X., Hu, J., Sánchez-Vallet, A., Deslandes, L., Llorente, F., Berrocal-Lobo, M., Keller, H., Barlet, X., SánchezRodríguez, C., Anderson, L. K., Somerville, S., Marco, Y., and Molina, A. 2007. Impairment of cellulose synthases required for Arabidopsis secondary cell wall formation enhances disease resistance. Plant Cell 19: 890-903.

Huet, G. 2014. Breeding for resistances to Ralstonia solanacearum. Front. Plant Sci. 5:715.

Ishihara, T., Mitsuhara, I., Takahashi, H., and Nakaho, K. 2012. Transcriptome analysis of quantitative resistance-specific response upon Ralstonia solanacearum infection in tomato. PLoS One 7:e46763.

Ivanchenko, M. G., Coffeen, W. C., Lomax, T. L., and Dubrovsky, J. G. 2006. Mutations in the Diageotropica $(D g t)$ gene uncouple patterned cell division during lateral root initiation from proliferative cell division in the pericycle. Plant J. 46:436-447.

Ivanchenko, M. G., Zhu, J., Wang, B., Medvecká, E., Du, Y., Azzarello, E., Mancuso, S., Megraw, M., Filichkin, S., Dubrovsky, J. G., Friml, J., and Geisler, M. 2015. The cyclophilin A DIAGEOTROPICA gene affects auxin transport in both root and shoot to control lateral root formation. Development 142:712-721.

Jia, N., Liu, X., and Gao, H. 2016. A DNA2 homolog is required for DNA damage repair, cell cycle regulation, and meristem maintenance in plants. Plant Physiol. 171:318-333.

Kazan, K., and Manners, J. M. 2009. Linking development to defense: Auxin in plant-pathogen interactions. Trends Plant Sci. 14:373-382.

Kidd, B. N., Kadoo, N. Y., Dombrecht, B., Tekeoglu, M., Gardiner, D. M., Thatcher, L. F., Aitken, E. A., Schenk, P. M., Manners, J. M., and Kazan, K.
2011. Auxin signaling and transport promote susceptibility to the rootinfecting fungal pathogen Fusarium oxysporum in Arabidopsis. Mol. PlantMicrobe Interact. 24:733-748.

Kiirika, L. M., Stahl, F., and Wydra, K. 2013. Phenotypic and molecular characterization of resistance induction by single and combined application of chitosan and silicon in tomato against Ralstonia solanacearum. Physiol. Mol. Plant Pathol. 81:1-12.

Kim, B. S., French, E., Caldwell, D., Harrington, E. J., and Iyer-Pascuzzi, A. S. 2016. Bacterial wilt disease: Host resistance and pathogen virulence mechanisms. Physiol. Mol. Plant Pathol. 95:37-43.

Kim, H., Kim, B. S., Shim, J. E., Hwang, S., Yang, S., Kim, E., IyerPascuzzi, A. S., and Lee, I. 2017. TomatoNet: A genome-wide cofunctional network for unveiling complex traits of tomato, a model crop for fleshy fruits. Mol. Plant 10:652-655.

Koornneef, A., Leon-Reyes, A., Ritsema, T., Verhage, A., Den Otter, F. C. Van Loon, L. C., and Pieterse, C. M. 2008. Kinetics of salicylatemediated suppression of jasmonate signaling reveal a role for redox modulation. Plant Physiol. 147:1358-1368.

Koornneef, A., and Pieterse, C. M. 2008. Cross talk in defense signaling. Plant Physiol. 146:839-844.

Křeček, P., Skupa, P., Libus, J., Naramoto, S., Tejos, R., Friml, J., and Zazímalová, E. 2009. The PIN-FORMED (PIN) protein family of auxin transporters. Genome Biol. 10:249.

Lebeau, A., Daunay, M. C., Frary, A., Palloix, A., Wang, J. F., Dintinger, J., Chiroleu, F., Wicker, E., and Prior, P. 2011. Bacterial wilt resistance in tomato, pepper, and eggplant: Genetic resources respond to diverse strains in the Ralstonia solanacearum species complex. Phytopathology 101: 154-165.

Li, P. C., Yu, S. W., Li, K., Huang, J. G., Wang, X. J., and Zheng, C. C. 2016. The mutation of Glu at amino acid 3838 of AtMDN1 provokes pleiotropic developmental phenotypes in Arabidopsis. Sci. Rep. 6:36446.

Lin, Y. M., Shih, S. L., Lin, W. C., Wu, J. W., Chen, Y. T., Hsieh, C. Y., Guan, L. C., Lin, L., and Cheng, C. P. 2014. Phytoalexin biosynthesis genes are regulated and involved in plant response to Ralstonia solanacearum infection. Plant Sci. 224:86-94.

Livak, K. J., and Schmittgen, T. D. 2001. Analysis of relative gene expression data using real-time quantitative PCR and the $2^{-\Delta \Lambda \mathrm{C}(\mathrm{T})}$ method. Methods 25:402-408.

Llorente, F., Muskett, P., Sánchez-Vallet, A., López, G., Ramos, B., Sánchez-Rodríguez, C., Jordá, L., Parker, J., and Molina, A. 2008. Repression of the auxin response pathway increases Arabidopsis susceptibility to necrotrophic fungi. Mol. Plant 1:496-509.

Ludwig-Müller, J. 2015. Bacteria and fungi controlling plant growth by manipulating auxin: Balance between development and defense. J. Plant Physiol. 172:4-12.

Madden, L. V., Hughes, G., and Van Den Bosh, F. 2007. The Study of Plant Disease Epidemics. APS Press, Saint Paul, U.S.A.

Mansfield, J., Genin, S., Magori, S., Citovsky, V., Sriariyanum, M., Ronald, P., Dow, M., Verdier, V., Beer, S. V., Machado, M. A., Toth, I., Salmond, G., and Foster, G. D. 2012. Top 10 plant pathogenic bacteria in molecular plant pathology. Mol. Plant Pathol. 13:614-629.

McAvoy, T., Freeman, J. H., Rideout, S. L., Olson, S. M., and Paret, P. L. 2012. Evaluation of grafting using hybrid rootstocks for managment of bacterial wilt in field tomato production. HortScience 47:621-625.

Mi, H., Poudel, S., Muruganujan, A., Casagrande, J. T., and Thomas, P. D. 2016. PANTHER version 10: Expanded protein families and functions, and analysis tools. Nucleic Acids Res. 44 (D1):D336-D342.

Millet, Y. A., Danna, C. H., Clay, N. K., Songnuan, W., Simon, M. D., Werck-Reichhart, D., and Ausubel, F. M. 2010. Innate immune responses activated in Arabidopsis roots by microbe-associated molecular patterns. Plant Cell 22:973-990.

Milling, A., Babujee, L., and Allen, C. 2011. Ralstonia solanacearum extracellular polysaccharide is a specific elicitor of defense responses in wilt-resistant tomato plants. PLoS One 6:e15853.

Mitchum, M. G., Hussey, R. S., Baum, T. J., Wang, X., Elling, A. A., Wubben, M., and Davis, E. L. 2013. Nematode effector proteins: An emerging paradigm of parasitism. New Phytol. 199:879-894.

Muday, G. K., Lomax, T. L., and Rayle, D. L. 1995. Characterization of the growth and auxin physiology of roots of the tomato mutant, diageotropica. Planta 195:548-553.

Navarro, L., Dunoyer, P., Jay, F., Arnold, B., Dharmasiri, N., Estelle, M., Voinnet, O., and Jones, J. D. 2006. A plant miRNA contributes to antibacterial resistance by repressing auxin signaling. Science 312: 436-439.

Ni, D. A., Sozzani, R., Blanchet, S., Domenichini, S., Reuzeau, C., Cella, R., Bergounioux, C., and Raynaud, C. 2009. The Arabidopsis MCM2 gene is essential to embryo development and its over-expression alters root meristem function. New Phytol. 184:311-322. 
O’Donnell, P. J., Schmelz, E. A., Moussatche, P., Lund, S. T., Jones, J. B., and Klee, H. J. 2003. Susceptible to intolerance-a range of hormonal actions in a susceptible Arabidopsis pathogen response. Plant J. 33: 245-257.

Oh, K., Ivanchenko, M. G., White, T. J., and Lomax, T. L. 2006. The diageotropica gene of tomato encodes a cyclophilin: A novel player in auxin signaling. Planta 224:133-144.

Petersson, S. V., Johansson, A. I., Kowalczyk, M., Makoveychuk, A., Wang, J. Y., Moritz, T., Grebe, M., Benfey, P. N., Sandberg, G., and Ljung, K. 2009. An auxin gradient and maximum in the Arabidopsis root apex shown by high-resolution cell-specific analysis of IAA distribution and synthesis. Plant Cell 21:1659-1668.

Prasath, D., Karthika, R., Habeeba, N. T., Suraby, E. J., Rosana, O. B., Shaji, A., Eapen, S. J., Deshpande, U., and Anandaraj, M. 2014 Comparison of the transcriptomes of ginger (Zingiber officinale Rosc.) and mango ginger (Curcuma amada Roxb.) in response to the bacterial wilt infection. PLoS One 9:e99731.

Qi, L., Yan, J., Li, Y., Jiang, H., Sun, J., Chen, Q., Li, H., Chu, J., Yan, C., Sun, X., Yu, Y., Li, C., and Li, C. 2012. Arabidopsis thaliana plants differentially modulate auxin biosynthesis and transport during defense responses to the necrotrophic pathogen Alternaria brassicicola. New Phytol. 195:872-882.

Ranocha, P., Denancé, N., Vanholme, R., Freydier, A., Martinez, Y., Hoffmann, L., Köhler, L., Pouzet, C., Renou, J. P., Sundberg, B., Boerjan, W., and Goffner, D. 2010. Walls are thin 1 (WAT1), an Arabidopsis homolog of Medicago truncatula NODULIN21, is a tonoplast-localized protein required for secondary wall formation in fibers. Plant J. 63:469-483.

Ranocha, P., Dima, O., Nagy, R., Felten, J., Corratgé-Faillie, C., Novák, O., Morreel, K., Lacombe, B., Martinez, Y., Pfrunder, S., Jin, X., Renou, J.-P., Thibaud, J. B., Ljung, K., Fischer, U., Martinoia, E., Boerjan, W., and Goffner, D. 2013. Arabidopsis WAT1 is a vacuolar auxin transport facilitator required for auxin homoeostasis. Nat. Commun. 4:2625.

Rivard, C. L., O'Connell, S., Peet, M. M., Welker, R. M., and Louws, F. J. 2012. Grafting tomato to manage bacterial wilt caused by Ralstonia solanacearum in the southeastern United States. Plant Dis. 96:973-978.

Robert-Seilaniantz, A., Grant, M., and Jones, J. D. 2011. Hormone crosstalk in plant disease and defense: More than just jasmonate-salicylate antagonism. Annu. Rev. Phytopathol. 49:317-343.

Robinson, M. D., McCarthy, D. J., and Smyth, G. K. 2010. edgeR: A Bioconductor package for differential expression analysis of digital gene expression data. Bioinformatics 26:139-140.

Saeed, A. I., Bhagabati, N. K., Braisted, J. C., Liang, W., Sharov, V., Howe, E. A., Li, J., Thiagarajan, M., White, J. A., and Quackenbush, J. 2006. TM4 microarray software suite. Methods Enzymol. 411:134-193.

Saeed, A. I., Sharov, V., White, J., Li, J., Liang, W., Bhagabati, N., Braisted, J., Klapa, M., Currier, T., Thiagarajan, M., Sturn, A., Snuffin, M., Rezantsev, A., Popov, D., Ryltsov, A., Kostukovich, E., Borisovsky, I., Liu, Z., Vinsavich, A., Trush, V., and Quackenbush, J. 2003. TM4: A free, open-source system for microarray data management and analysis. Biotechniques 34:374-378.

Sang, Y., Silva-Ortega, C. O., Wu, S., Yamaguchi, N., Wu, M. F., Pfluger, J., Gillmor, C. S., Gallagher, K. L., and Wagner, D. 2012. Mutations in two noncanonical Arabidopsis SWI2/SNF2 chromatin remodeling ATPases cause embryogenesis and stem cell maintenance defects. Plant J. 72:1000-1014.

Shen, W. H., and Xu, L. 2009. Chromatin remodeling in stem cell maintenance in Arabidopsis thaliana. Mol. Plant 2:600-609.

Spaepen, S., Vanderleyden, J., and Remans, R. 2007. Indole-3-acetic acid in microbial and microorganism-plant signaling. FEMS Microbiol. Rev. 31:425-448.

Spiegelman, Z., Omer, S., Mansfeld, B. N., and Wolf, S. 2017. Function of Cyclophilin1 as a long-distance signal molecule in the phloem of tomato plants. J. Exp. Bot. 68:953-964.
Spoel, S. H., Johnson, J. S., and Dong, X. 2007. Regulation of tradeoffs between plant defenses against pathogens with different lifestyles. Proc. Natl. Acad. Sci. U.S.A. 104:18842-18847.

Spoel, S. H., Koornneef, A., Claessens, S. M., Korzelius, J. P., Van Pelt, J. A., Mueller, M. J., Buchala, A. J., Métraux, J. P., Brown, R., Kazan, K., Van Loon, L. C., Dong, X., and Pieterse, C. M. 2003. NPR1 modulates cross-talk between salicylate- and jasmonate-dependent defense pathways through a novel function in the cytosol. Plant Cell 15:760-770.

Takatsuka, H., and Umeda, M. 2015. epigenetic control of cell division and cell differentiation in the root apex. Front. Plant Sci. 6:1178.

Tans-Kersten, J., Huang, H., and Allen, C. 2001. Ralstonia solanacearum needs motility for invasive virulence on tomato. J. Bacteriol. 183: 3597-3605.

Teixeira, M. A., Wei, L., and Kaloshian, I. 2016. Root-knot nematodes induce pattern-triggered immunity in Arabidopsis thaliana roots. New Phytol. 211:276-287.

Thimm, O., Bläsing, O., Gibon, Y., Nagel, A., Meyer, S., Krüger, P., Selbig, J., Müller, L. A., Rhee, S. Y., and Stitt, M. 2004. MAPMAN: A userdriven tool to display genomics data sets onto diagrams of metabolic pathways and other biological processes. Plant J. 37:914-939.

Thoquet, P., Olivier, J., Sperisen, C., Rogowsky, P., Laterrot, H., and Grimsley, N. 1996a. Quantitative trait loci determining resistance to bacterial wilt in tomato cultivar Hawaii7996. Mol. Plant-Microbe Interact. 9:826-836.

Thoquet, P., Olivier, J., Sperisen, C., Rogowsky, P., Prior, P., Anais, G., Mangin, B., Bazin, B., Nazer, R., and Grimsley, N. 1996b. Polygenic resistance of tomato plants to bacterial wilt in the French West Indies. Mol. Plant-Microbe Interact. 9:837-842.

Tiryaki, I., and Staswick, P. E. 2002. An Arabidopsis mutant defective in jasmonate response is allelic to the auxin-signaling mutant axrl. Plant Physiol. 130:887-894.

Tomato Genome Consortium. 2012. The tomato genome sequence provides insights into fleshy fruit evolution. Nature 485:635-641.

Trapnell, C., Pachter, L., and Salzberg, S. L. 2009. TopHat: Discovering splice junctions with RNA-Seq. Bioinformatics 25:1105-1111.

Valls, M., Genin, S., and Boucher, C. 2006. Integrated regulation of the type III secretion system and other virulence determinants in Ralstonia solanacearum. PLoS Pathog. 2:e82.

Wang, J.-F., Ho, F.-I., Truong, H. T. H., Hugan, S.-M., Balatero, C. H., Dittapongpitch, V., and Hidayati, N. 2013. Identification of major QTLs associated with stable resitance of tomato cultivar 'Hawaii 7996' to Ralstonia solanacearum. Euphytica 190:241-252.

Wang, J. F., Olivier, J., Thoquet, P., Mangin, B., Sauviac, L., and Grimsley, N. H. 2000. Resistance of tomato line Hawaii7996 to Ralstonia solanacearum Pss4 in Taiwan is controlled mainly by a major strainspecific locus. Mol. Plant-Microbe Interact. 13:6-13.

Wieckowski, Y., and Schiefelbein, J. 2012. Nuclear ribosome biogenesis mediated by the DIM1A rRNA dimethylase is required for organized root growth and epidermal patterning in Arabidopsis. Plant Cell 24: 2839-2856.

Zobel, R. W. 1974. Control of morphogenesis in the ethylene-requiring tomato mutant, diageotropica. Can. J. Bot. 52:735-741.

Zuluaga, A. P., Solé, M., Lu, H., Góngora-Castillo, E., Vaillancourt, B., Coll, N., Buell, C. R., and Valls, M. 2015. Transcriptome responses to Ralstonia solanacearum infection in the roots of the wild potato Solanum commersonii. BMC Genomics 16:246.

\section{AUTHOR-RECOMMENDED INTERNET RESOURCES}

PANTHER GO analysis tool: http://www.pantherdb.org Venny interactive tool: http://bioinfogp.cnb.csic.es/tools/venny/index.html 